\title{
A DSS model for the governance of sustainable rural landscape: a first application to the cultural landscape of Orcia Valley (Tuscany, Italy)
}

Massimo Rovai - massimo.rovai@unipi.it - University of Pisa, DISAAA, Via del Borghetto, 56124 Pisa; Italy

Maria Andreoli - maria.andreoli@ unipi.it; University of Pisa, DISAAA, Via del Borghetto, 56124 Pisa; Italy

Simone Gorelli - sgorelli@emasrl.eu - EMA srl

Heikki Jussila - heikkitapio.jussila@gmail.com - Laboratorio di Studi Rurali Sismondi . Italia 


\section{1. Introduction and State of the Art ${ }^{1}$}

2 The European Landscape Convention (ELC) defines landscape as "an area, as perceived by

3 people, whose character is the result of the action and interaction of natural and/or human

4 factors" and underlines that "a landscape forms a whole, whose natural and cultural components

5 are taken together, not separately" (Council of Europe, 2000). This not only asks for an

6 integration of the methodologies and approaches that concern bio-physical and socio-cultural

7 aspects, but asks also for the adoption of proper tools able to highlight the effects of human

8 activities on landscape. Indeed, as highlighted by Conrad et al. (2011a), the Explanatory Report

9 of ELC observes that landscape protection, management and planning can be a complex matter

10 necessitating multi-disciplinary work. The need for public intervention in this field derives from

11 the economic characteristics of landscape; indeed, rural landscape is a pure public good and an

12 externality (positive or negative) of farming and other economic activities that exploit and

13 modify the land. Although landscape protection could be pursued by means of "command and

14 control" policies, based on the definition of standards to be respected on land transformation,

15 nevertheless standards are usually scarcely effective and often opposed by people who suffer for

16 their implementation. Besides, command and control policies are ineffective in opposing passive

17 transformations due to an activity being abandoned that in some way contributes to the landscape

18 maintenance (Tempesta, 2014), as in the case of agriculture, especially in some rural marginal

19 regions. In recent years there has been a growing awareness of the multifunctional role played by

20 agricultural activities (OECD, 2001), which not only provide food and fibre for producing goods

21 but also services, such as environmental protection or landscape conservation. These services are

1. Due to the specificity of landscape problems, we have preferred, when possible, literature on international journals referring to the Italian situation 
22 usually defined as "no commodity outputs" and according to their type and the context in which

23 they are produced, they can develop into proper economic activities (farm diversification, e.g.

24 selling services relating to hydrological protection or forest management) or remain outside the

25 market. In this last case it is important to understand if these services are necessarily provided, or

26 not, by agricultural activities. Indeed, while in the first case policies aiming at maintaining

27 agricultural activities may automatically maintain also an adequate level of no-commodity

28 outputs, in the second case, specific interventions will be required in order to maintain such a

29 level. De Groot et al. (2010) propose that the concept of ecosystem services and values should be

30 integrated in landscape planning, management and decision making, changing the focus on

31 ecosystem services production from agriculture to landscape, although agriculture remains the

32 main driver for the change of rural landscape. In this framework it is paramount to study and to

33 understand the impacts of agricultural policies, e.g. the Common Agricultural Policy (CAP) of

34 the European Union, which can play both the role of driver of landscape change and that of

35 response to landscape deterioration. Indeed, while the past policy of direct payments, with the

36 consequent intensification of agriculture and the research of economies of scale, has brought

37 about a simplification and homogenization of the rural landscape (see e.g. Agnoletti et al., 2011,

38 van Zanten et al. 2013), Pillar 2 measures, by promoting rural development, have often prevented

39 abandonment and land deterioration. The vast literature dealing with the ex-ante and ex-post

40 evaluation of CAP impacts on rural landscapes (e.g. Brady et al, 2009, Lefebvre et al., 2012,

41 Agnoletti et al., 2011) confirms the growing interest in the analysis of such policies as drivers of

42 the level of ecosystem services provided by landscape. After the last CAP reform and the

43 introduction of greening rules, landscape conservation and management can be directly promoted

44 also under Pillar 1, although there is a concern that direct payment effects on landscape could be 
- as in the past - significant and negative. Besides, albeit many Authors stress the need to

46 reconcile production and environmental integrity (see, e.g. Costanza et al, 1997; Robertson and

47 Swinton, 2005), there is the risk of an alteration in the balance between policies promoting

48 productive and non-productive functions of agriculture. Thus, while in more productive

49 agricultural areas there is the risk of an intensification, due to the increase in world population

50 and the consequent increase on demand of agricultural products, which could cause famine and

51 social tensions, less fertile areas risk the abandonment because of too high costs of production.

52 Due to its spatial characteristic, landscape is also ruled by territorial planning, which states rules

53 and standards about land use and transformation, usually through command and control tools, as

54 stated above. Territorial planning is usually regulated by laws that are more area-specific than

55 agricultural policies, being mainly related to the regional and sub-regional levels. Last but not

56 least, there are other policies, mainly dealing with environmental issues (see, e.g. rules dealing

57 with nitrogen use or the use of water), that can influence agriculture and landscape services.

58 These policies deal with issues that have to be faced at different spatial units (e.g. landscape

59 systems, hydrological catchments, administrative areas, ecosystems, protected areas, etc.), thus

60 implying that analyses should be able to work at different scales and to integrate them. Besides

61 "spatial" scales also "temporal" scales are very important, especially in the case of historical

62 cultural landscape. A review of the methodological problems about scale arising in

63 interdisciplinary research on landscape is provided by Higgins et al. (2012).

64 As we have above stated, landscape conservation, management and planning is a very complex

65 task, implying not only interdisciplinary but also transdisciplinary approaches. The need for an

66 interdisciplinary approach is due to the fact that landscape quality and the ecosystem services

67 that it provides depend on many features belonging to different research fields. According to 
Vizzari (2011) potential landscape quality relies on three different classes of components,

69 namely "Physical-naturalistic", "Historical-cultural" and "Social-symbolic". Conrad et al.

70 (2011a) stress that still "there appears to be a bias in academia towards ecological concerns,

71 which contrasts with the more holistic approach adopted in landscape policy". According to

72 Agnoletti (2014), there is also a bias towards nature and environment at policy level, insofar

73 international directives involving landscapes are often overlapping the idea of nature with that of

74 landscape, encouraging renaturalization, particularly in the form of forest cover, and neglecting

75 ancient landscape patterns. This "reduction" of landscape to elements mostly related to nature

76 and environment emerges also from a survey on landscape aspirations in Ghent area (Sevenant

77 and Antrop, 2010, p. 384).

78 As regards the need of a transdisciplinary approach in landscape research, this asks for an

79 involvement both of academic researchers and non-academic partners, such as managers,

80 administrators, and the local public (Sevenant and Antrop, 2010) with the aim to prevent the risk

81 of an "expert-led" landscape elitism, focusing resources and attention only on iconic landscape

82 (Scott, 2011). Following the ELC statement that, "landscape is an issue which affects the whole

83 population and care for the landscape requires collaboration between a wide range of individuals

84 and organisations" (Conrad et al 2011a) many researchers have focused on the problems of

85 people's perceptions (Howley, 2011; Howley et al., 2012; Conrad et al., 2011b; Tempesta, 2010;

86 Tempesta, 2014), people's aspirations about landscape (Sevenant and Antrop, 2010) and public

87 active involvement in policies. This implies a shift from top-down "command and control" tools

88 towards models of Governance where local population have a role (see, e.g., Scott, 2011;

89 Southern et al., 2011). 
90 As regards Tuscany, where the case study area is situated, although the high reputation of

91 outstanding beauty of many Tuscany landscapes could bring about the risk of "elitism",

92 nevertheless the diffuse awareness of the importance of landscape, also for economic reasons,

93 promotes the willingness of local stakeholders to participate to landscape governance (see, e.g.

94 Gaggio, 2014).

95 In this framework, a proper tool able to support governance decision for sustainable rural

96 landscape should be able to consider and integrate all the above mentioned aspects.

97 In this paper we propose a general framework model for the governance of sustainable rural

98 landscape and a first, simplified application of this model that has been tested on Orcia Valley in

99 Tuscany, a Region with a very high landscape reputation. According to Van Assche and Lo

100 (2011) "The original drivers of value formation, and thus asset creation, are to be found in civic

101 traditions and in early tourism (English, later German), in turn driven by literature, painting and

102 by certain images of a well-rounded education for a gentleman". In more recent times, also well-

103 known movies set in Tuscany Region, such as "The English Patient" or "A room with a view"

104 have contributed to the international reputation of its landscape. Tuscany landscape reputation is

105 important also in connection with origin denomination food products (see, e.g. Miele and

106 Murdoch, 2002), and could have a great economic relevance in terms of place branding in many

107 fields (see, e.g.: Bellini et al., 2011; Gaggio, 2011). Inside Tuscany, Val d'Orcia is particularly

108 well known as it is a UNESCO Heritage site, as detailed in the case-study paragraph.

109 This paper analyses and evaluates the connections and feedbacks between farmers' strategies,

110 agricultural policies and landscape evolution since it is assumed that the evolution of rural

111 landscape (and of the ecosystem services it provides) mainly depends on changes of farms'

112 productive arrangements. These latter, in turn, depend on specific business strategies that are 
113 conditioned by the specific set of available (physical, economic, human, etc.) resources and by

114 external factors such as agricultural policies and commodity market trends. In the case of Orcia

115 Valley, indeed, the CAP and durum wheat high prices have had a key role in bringing about the

116 current landscape. At present, the Orcia Valley landscape is considered as an identity element

117 and a strategic factor for this territory's good reputation (Antrop, 2005) and, although the local

118 community would like to maintain or to develop it in a sustainable way (001, 2007 masked for

119 blind review), it is nevertheless under threat due to the change of CAP. In this framework, the

120 aim of this paper is to propose a decision support system able, for a specific area, firstly to

121 improve the knowledge of the possible effects on landscape and its ecosystem services deriving

122 from changes in farmers' choices due to internal and external factors, and then, to suggest

123 possible area-tailored interventions to counteract the significant and negative effects that CAP

124 can produce. Although the implementation on the case-study has focused on the main type of

125 ecosystem services provided by the area, namely cultural ecosystem services, nevertheless it is

126 the Authors' opinion that the results are able to highlight the potential usefulness of the proposed

127 model.

128 The model is based on the integration of approaches, such as Geographical Multi-Criteria

129 Analysis; advanced GIS-based geo-processing tools and participatory techniques aiming to

130 understand local people perception and foresee local stakeholders' behaviours through focus-

131 groups and dedicated interviews. 
132 2. The model for the governance of sustainable rural landscapes: general framework and methodology applied to a cultural landscape.

\subsection{The general framework}

134 In this chapter, first of all an outline of the general framework methodology is provided; this

135 general model, in our opinion, can be implemented in a vast range of landscape/areas. Then a

136 more detailed description of the methodology that could be applied to a cultural landscape, such

137 as the one of the case-study analysis, is given. In both cases, some adaptations may be needed

138 insofar landscape evolution and governance of an area is deeply connected with the institutional,

139 cultural and socio-economic framework in which public institutions and stakeholders operate

140 (see, e.g. Gaggio, 2014); consequently the most relevant features to be taken into account vary

141 from area to area.

142 The general framework for the governance model of sustainable rural landscape (Figure 1)

143 requires:

144 - a evolutionary analysis based, from the one hand, on statistical and territorial analyses, and,

145 from the other hand, on participatory tools, able to highlight the evolutionary path that has

146 brought about the current situation of the area and its landscape;

147 a current situation analysis based on the hypothesis that both territorial characteristics and

148 farm characteristics, through farmers strategies, are having an impact on landscape and its

149 ecosystem services. Farm strategies are also influenced by external factors such as

150 commodity market trends, and policies, laws and regulations, which could be compulsory

151 (e.g. environmental or land use standards) or voluntary (e.g. some of the aid given to the

152 agricultural sector). Stakeholders could consider Ecosystem Services provision not

153 satisfactory in the present situation or at risk for the future and thus could ask for some 
154 intervention. Policies and laws are not only determinants of the initial landscape situation

155 (see evolutionary analysis), but also tools for modifying it in the future, in the case that the

156 effects of farmers strategies on landscape ecosystem services (see present time loop) ask for

157 an intervention. In this case, the loop goes on through the identification of the priorities in

158 terms of areas and ecosystem services whose production has to be improved, and the choice

159 of actions (through existing or new policies, laws and regulations) that are more effective

160 and efficient in facing the problem.

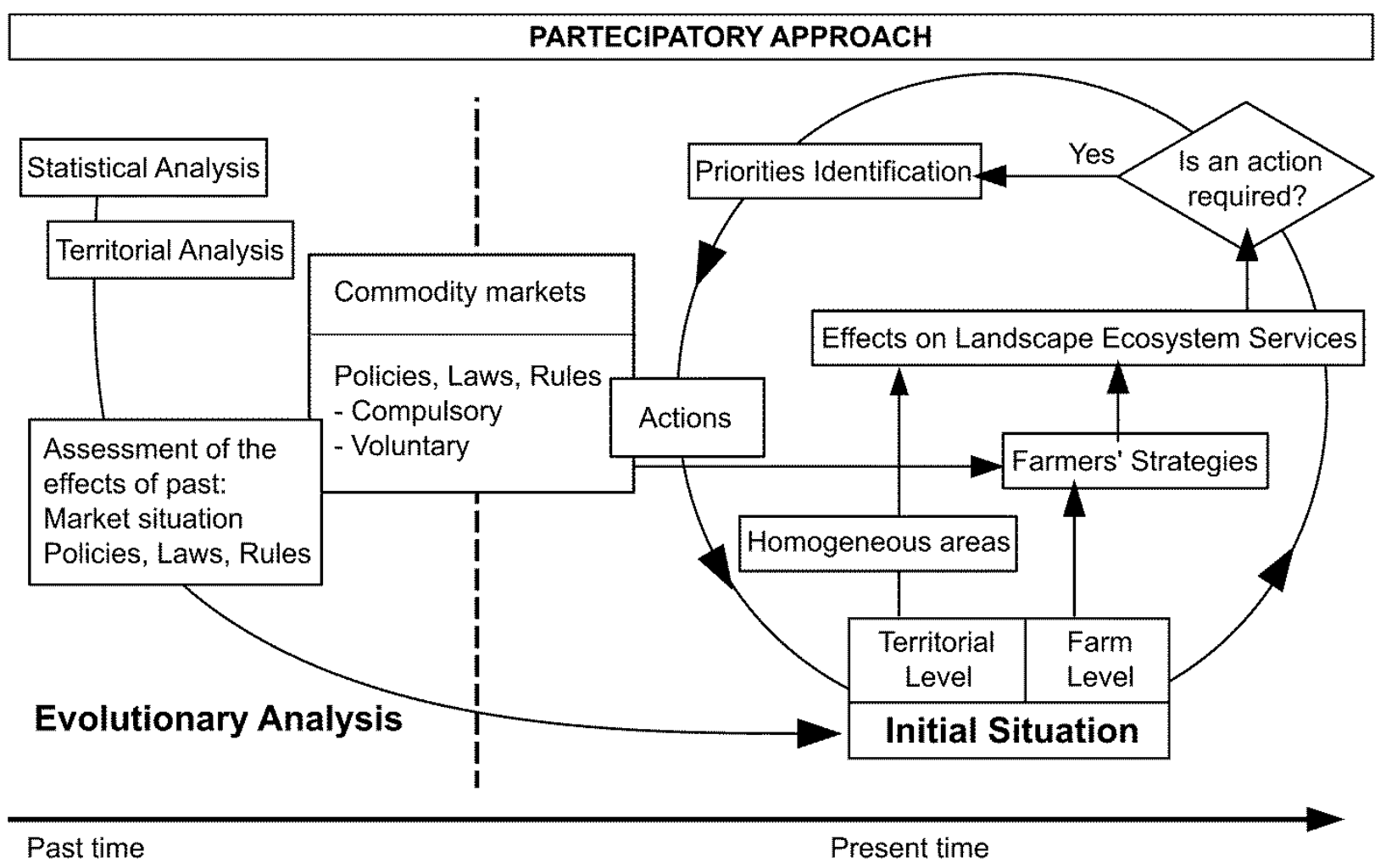

162 Figure 1. Flow chart of the model for the governance of sustainable rural landscape.

\subsection{The role of GIS-based Multicriteria Decision Aid Techniques and participative approach}

163 As above stated, in our "model for the governance of sustainable rural landscapes" all

164 evaluations are based on the integration between tools proper of territorial and environmental

165 analysis - as GIS-based Multicriteria Decision Aid Techniques - and participatory instruments 
166 (Southern et al., 2011). In particular, both territorial and farm analyses are implemented via

167 Geographic Multicriteria Decision Aiding Techniques able to rank the spatial decisional

168 alternatives under study according to their specific and often conflicting evaluation criteria,

169 which are represented through standardized map layers (Malczewski, 1999, 2006a, 2006b).

170 Among the several multicriteria analysis techniques described in literature (Beinat and Nijkamp,

171 1998; Mendoza and Martins, 2006), the multi-attribute Saaty's Analytical Hierarchical Process

172 (AHP) has been chosen (Saaty, 1980, 2004, 2008; Saaty and Vargas, 1994; Vargas, 1990). This

173 method constructs the evaluation process through distinct phases, assuming as a principle the

174 possibility to segment a complex decision-making problem into smaller and simpler sub-

175 problems composing a hierarchical structure, within which it is always possible to measure the

176 influence each part has on the whole system.

177 As a matter of fact, in the AHP method, three different stages can be identified: a) analysis, b)

178 pair wise comparisons, and c) hierarchical re-composition. The analysis phase consists in

179 defining a hierarchical structure able to encompass the most important elements for the decision

180 problem; a first level is represented by the general aim of the evaluation (goal), then there are

181 some intermediate levels represented by criteria, attributes and sub-attributes, while the last level

182 is typically represented by decision alternatives. In a geographical multicriteria decision making

183 analysis, criteria, attributes and alternatives are represented in the physical space of territory;

184 thus the hierarchical structure generally ends at the attribute or sub-attribute level (Siddiqui et al.,

185 1996). Therefore, decisional alternatives can be represented, under a GIS framework, via points,

186 lines, polygons or pixels that contain the attributes values. In this study, alternatives are

187 geographically represented by polygons that in the farm analysis locate farms and plots areas,

188 while in the territorial analysis they locate landscape systems and subsystems since planning 
rules could vary according to the system or subsystem. Since it is quite difficult to implement a

190 general model, taking into account historical evolution and present farm and territorial features,

191 able to adequately represent all the existing links, our model hypothesizes that - in order to

192 indentify the relevant attributes - the score of criteria could be summed up by the weighted sum

193 of the lower hierarchical level, according to the described methodology provided by Saaty. The

194 results of the analysis should be validated by stakeholders, in order to check that there aren't

195 significant impacts on the quality of results due to this simplification.

196 Within this model, the participatory method has a fundamental role as it allows to collect

197 information at different levels $(002,2008$ masked for blind review) and to involve the whole

198 population - and not only experts - in the governance of landscape, as required by a

199 transdisciplinary approach. During the initial phase, participation could allows to understand: a)

200 the stakeholders' perception as regards present landscape distinguishing elements and the level

201 of ecosystem services provided; b) the evolutionary dynamics they have had in time, c) the main

202 determinants (market trends, planning and policy tools) that have influenced farmers' strategies

203 up to the present situation and that could influence farm evolutionary paths. Evolutionary

204 analysis is not only important for cultural landscape, since Italian recent history demonstrates

205 that the "local memory" could have been a useful tool to avoid present land management

206 mistakes, e.g. in the case of risk of floods or landslides due to the excessive weight of the

207 vegetation cover.

208 In the farm and territorial analyses, participation mainly involves the discussion with different

209 stakeholders about criteria, sub-criteria and attributes to be introduced in the analysis, to be

210 chosen among those proposed by literature. The final choice of attributes should take into

211 account also the interviews to key informants; e.g. the type of cropping technique and the type of 
212 market channel have been introduced in the case-study analysis because the participative

213 approach has confirmed that farmers that adopt organic techniques and sell their products

214 directly on farm have a attitude towards landscape that is different from the one of

215 "conventional” farmers. Scores to attributes are given by stakeholders through pairwise

216 comparison. For this phase of the participative approach, mainly face to face interviews to key

217 informants should be performed, while the results of the analysis should be discussed in focus

218 groups with the participation of all the category of stakeholders.

219 Participation through focus groups allows also to individuate priorities for response actions able

220 to promote a sustainable rural landscape, according to stakeholders' opinion about Ecosystem

221 Services and their influence on well-being. The discussion has the aim to single out compromise

222 solutions, able to involve in their implementation the highest number possible of stakeholders.

223 Thus, the role of participation in the model is not only limited to informative or consultative

224 processes, but it actively contributes to the results. For this reason in the figure describing the

225 general model (Figure 1) the participatory approach is presented in the top part and it is supposed

226 to contribute both to the evolutionary analysis and to the part of the governance model, aiming to

227 highlight the best actions to be implemented, based on the present situation. From a public

228 institutions viewpoint, actions should be chosen taking into account the level of effectiveness and

229 efficiency characterizing each command and control and voluntary tool (see, e.g. Tempesta,

230 2014). The governance model should be able to individuate priorities and intervention methods

231 for each homogeneous territorial ambit, in accordance with public priorities, farmers' strategies

232 and specific rural landscape characteristics. 


\subsection{Testing the model on a cultural landscape: the applied methodology}

233 Since the management of ecosystem services provided by landscape is very complex, in testing

234 our model we have decided to focus on rural cultural landscapes where the main ecosystem

235 services (ES) provided are cultural ones (Wu, J. 2013, fig. 6). As stated by Wu, "from a multi-

236 scale perspective, Daly's strong sustainability at a broad scale may not be achieved without a

237 proper combination of weak and absurdly strong sustainability on smaller scales”. From a spatial

238 point of view, this, in our opinion, could mean that on small scales it is usually not possible to

239 require very strong sustainability for all the ecosystem services provided and thus it is necessary

240 to focus on the ones that are paramount in the analysed context. Furthermore, on a small scale it

241 could be very difficult to evaluate the contribution of an area in providing ecosystem services

242 like the one relating to water regulation and climate change, since those have to be analysed at a

243 larger scale. For the above mentioned reasons, the problem of sustainability in the applied

244 methodology focuses on the research of a dynamic balance between human development and

245 environmental protection (Bruntland Report, WCED 1987), namely the permanence of a

246 landscape for future generation without compromising the chance of present generation to make

247 a living in the area (social and economic sustainability).

248 In the following part we present the details of how this approach could be implemented in a

249 cultural landscapes, mostly referring to the specific methodology that has been applied to the

250 case study, although some hints on how the model could be adapted to different landscape

251 contexts are given.

\section{The evolutionary analysis}

252 As already anticipated, firstly our model requires a historical and evolutionary investigation

253 (Figure 1 - left part), in order to evaluate the effects of agricultural policies and other driving 
254 forces on farmers' choices in relation to agro-territorial and landscape evolutions. While in our 255 model we have considered only farmers as "agents" directly influencing landscape, it would be 256 possible, if relevant, to widen the analysis to other landscape managers (see van Zanten et al., 257 2013). This phase aims to clarify the relations among the social, economic, and environmental 258 systems, investigating their contribution to ecosystem services provision. When analysing a 259 cultural landscape, the focus is usually on landscape configuration and on the forces by which 260 landscape has been shaped. This phase includes the following steps: a) identification of social 261 and demographic dynamics, b) analysis of the evolution both of agricultural and forest 262 cultivations, and of the most representative vegetation for the study area and c) study of their 263 connections with the local culture (Agnoletti and Maggiari, 2004; Sereni, 1997). Landscape is 264 made of elements that cannot be simply summed, but rather it is formed by a multitude of 265 historical (both present and past) relations that join such elements. It is therefore necessary to 266 identify the cultural identity of a territory, which is expressed by complex links among natural 267 and anthropic factors evolving during the time (Ihse, 1990; Mayes, 2010). The historical

268 knowledge has been organized in two phases; a diachronic reading, with the aim to understand 269 temporal transformations, and a synchronic reading, with the aim to find out traces of the past 270 that are still present and in order to provide a comprehensive picture of the present situation. The 271 comparison between cartographies and aerial orthophotos, relating both to historical and present 272 situations, allows to individuate the permanencies among anthropic settlements and territorial 273 contexts, which are visible in the scheme of spaces, materials, visual and symbolic features.

274 Indeed, as Agnoletti et al. state (2011, p. 122) "the landscape is the result of the centuries-old

275 interaction between man and the environment, and so to define an element of the landscape as 276 characteristic the land use dynamics and changes to the landscape must be evaluated over a long 
277 time span". Visual and symbolic features are important because landscape knowledge not only

278 implies a study of physical and historical spaces as landscape is also the place of memory.

279 The acquired historical knowledge permits to point out the characteristics that are specific of

280 each landscape in order to direct planning choices in the correct way. Such knowledge can be

281 acquired both via social and historical studies, and consulting the archives of local communities.

282 Although in the implementation of the model, due to the role of cultural landscape of the case-

283 study area, we have focuses on land use and elements of the landscape, such as hedges and

284 isolated trees, in landscapes where regulating, supporting or provisional services are more

285 important, statistical data and previous researches could be used for tracing the evolution of

286 parameters that are more focused on the natural environment. In this case, the analysis should

287 include, e.g., studies on the loss of biodiversity, on erosion or water management, on air, water

288 and soil pollution due to the inputs and wastes linked to agriculture or other anthropic activities.

289 Then, the analysis investigates the current scenario (right part; see "initial situation") both from a

290 territorial and farm viewpoints.

\section{The territorial analysis}

291 The territorial analysis is necessary to classify a territory into homogeneous ambits as regards the

292 level of ecosystem services that they are able to provide and the risk that anthropic activities

293 could negatively impact on them. In the case of a cultural landscape, such as the one analysed in

294 the case-study, the analysis needs to focus on landscape quality and sensitivity, related to the

295 diffusion and density of several landscape identification elements and on the presence of relevant

296 environmental resources, such as areas with environmental interest. Indeed, area with

297 environmental interest are usually characterized both by a high value, and by a high

298 vulnerability. 
299 With this aim, a geographic multicriteria analysis has been used to create a thematic map of

300 homogeneous areas, which have specific intervention priorities due to their landscape features. In

301 case of landscape where cultural aspects are prominent, the analysis of the main features at

302 spatial level should focus on sensitivity, which we propose to evaluate by combining two criteria

303 called intrinsic value and vulnerability. The first one represents the absolute worth of the

304 analysed element, while the second one indicates the landscape fragility connected with the

305 modifications induced by anthropic activities.

306 In the case of cultural landscape where agriculture is quite intensive or where there are

307 significant environmental problems, the analysis should broaden and include also aspects other

308 than landscape sensitivity, by introducing parameters such as biodiversity, erosion, water

309 regulation, water, soil and air pollution, etc.

310 The territorial analysis allows to determine landscape sensitivity values for each portion of an

311 area, and consequently, to individuate and locate zones with similar level of adaptability to the

312 modifications induced by anthropic activities. This analysis and the resulting zoning is therefore

313 necessary to define the most critical zones for the territorial and landscape planning phases,

314 namely the areas with high worth and high fragility, where anthropic activities could easily cause

315 a noticeable loss in terms of cultural ecosystem services and of environmental quality in areas of

316 high environmental value.

317 The methodology of analysis enables to elaborate all the information relating to landscape

318 sensitivity and to summarize them into a synthetic index: the Sensitivity Index (SI). As

319 previously described, the landscape sensitivity analysis is carried out via a geographical multi- 
320 criteria decision making technique, by using the Saaty's Hierarchical Analysis. Evaluation

321 criteria, attributes, sub-attributes valuation classes and scores ${ }_{2}$ are shown in detail in Table 1.

322 Table 1 -Territorial Analysis: Criteria, attributes, sub-attributes, valuation classes and scores

\begin{tabular}{|c|c|c|}
\hline & Valuation classes & Score \\
\hline CRITERION: I & trinsic Value & \\
\hline $\begin{array}{l}\text { Attribute: Histo } \\
\text { Sub-attributes: }\end{array}$ & ical-Environmental Value & \\
\hline & Shannon Dominance Index $<0.2$ & 3 \\
\hline & $0.2>$ Shannon Dominance Index $>0.4$ & 2 \\
\hline Fragmentation & $0.4>$ Shannon Dominance Index $>0.6$ & 1 \\
\hline & Shannon Dominance Index $>0.6$ & 0 \\
\hline & $<10 \%$ of territory affected by modifications & 3 \\
\hline & from $10 \%$ to $50 \%$ of territory affected by modifications & 2 \\
\hline Persistence & from $51 \%$ to $80 \%$ of territory affected by modifications & 1 \\
\hline & $>80 \%$ of territory affected by modifications & 0 \\
\hline & $>5 \%$ of territory involved & 3 \\
\hline & $3-5 \%$ of territory involved & 2 \\
\hline Uniqueness & $1-2 \%$ of territory involved & 1 \\
\hline & $<1 \%$ of territory involved & 0 \\
\hline & ratio $=1$ & 3 \\
\hline & ratio from 1.1 to 1.5 & 2 \\
\hline Integrity & ratio from 1.51 to 5 & 1 \\
\hline & ratio $>5$ & 0 \\
\hline & ratio $>0.15$ & 3 \\
\hline & ratio from 0.11 to 0.15 & 2 \\
\hline Visibility & ratio from 0.01 to 0.10 & 1 \\
\hline & ratio $=0$ & 0 \\
\hline Attribute: Frequ & entation & \\
\hline & $>25 \%$ of affected territory & 3 \\
\hline & from $11 \%$ to $25 \%$ of affected territory & 2 \\
\hline & from $1 \%$ to $10 \%$ of affected territory & 1 \\
\hline & $0 \%$ of affected territory & 0 \\
\hline CRITERION: & ulnerability & \\
\hline Attribute: Inter & isibility & \\
\hline & high & 3 \\
\hline & medium & 2 \\
\hline & low & 1 \\
\hline & null & 0 \\
\hline
\end{tabular}

Attribute: Environmental Value

$>30 \%$ of territory occupied by significant environmental areas $\quad 3$

2 Although scores should belong to the analysis of the case-study, since they have been attributed in the framework of the participative approach, we decided to anticipate them rather than duplicate the table 
6-30\% of territory occupied by significant environmental areas $\quad 2$

$1-5 \%$ of territory occupied by significant environmental areas 1

$0 \%$ of territory occupied by significant environmental areas $\quad 0$

323 Score: $0=$ null, $1=$ low, $2=$ =medium, 3=high

324 The four levels hierarchical structure and the score given were determined during the

325 consultation phase with the stakeholders in the case-study analysis, and for this reason it is partly

326 area-specific.

327 As above described, the territorial analysis is performed by measuring two criteria: Intrinsic

328 Value and Vulnerability. The criterion Intrinsic Value is analysed through two attributes called

329 "Historic-environmental Value" and "Frequentation". The Historic-environmental Value

330 expresses the interaction between natural and anthropic factors and it is analysed through the

331 following sub-attributes: Fragmentation, Persistence, Uniqueness, Integrity, and Visibility.

332 The Fragmentation is evaluated by Shannon dominance index (Farina, 2006; Shannon and

333 Weaver, 1949), which enables to study the composition of the mosaic made by landscape pixels.

334 The Persistence is evaluated through the share of territory affected by modifications, in relation

335 to the number and historical persistence of landscape elements, derived from the historic analysis

336 and the interviews with local key informants. This sub-attribute is computed by Sharpe Change

337 Index (SCI) (Farina, 2006; Sharpe et al., 1982). The higher the SCI, the lower the landscape

338 elements persistence.

339 For the determination of the sub-attribute called Uniqueness, the most typical and unique

340 landscape elements (Regione Toscana, n.d.) that occupy areas within the Orcia Valley have been

341 singled out in the study area; high percentages of occupied surface correspond to high

342 uniqueness values. 
343 The sub-attribute called Integrity concerns the current state of conservation and the geographical

344 extension of a historic landscape that may have worsened in time. This sub-attribute is calculated

345 by computing the surface ratio of the various land use at different time (1954-2002)s and

346 determining the average variation.

347 The sub-attribute Visibility is based on a visibility analysis (performed via GIS) from specific

348 observation points (roads, panoramic points and paths, inhabited places, etc.). This analysis

349 enables to compute the number of points that are simultaneously seen from each elementary cell,

350 namely an area of $10 \mathrm{~m}^{2}$, of a grid that covers the entire study area. The value of this sub-

351 attribute is calculated by multiplying the visibility index of each i-subarea, where subareas are

352 delimited on the base of homogeneous features as regards constraints and goals in terms of

353 landscape quality level, by its correspondent extension; such products are therefore summed and

354 then divided by the total surface of the entire area. The greater the value of such ratio, the higher

355 the Visibility for the specific area. The aim of this sub-attribute is to give priority of intervention

356 to those portions of rural landscape that, at parity of worth, have higher chances to be seen due to

357 their spatial location.

358 The attribute called Frequentation concerns the presence of landscape observers in the Orcia

359 Valley and it is calculated as a surface percentage of the most frequented zones, such as urban

360 areas, roads, scattered buildings, panoramic paths, etc. From this point of view, at parity of worth

361 and visibility level, priority should be given to the actions relating portions of landscape that

362 have higher chances to be seen, due to the fact that there are observers which, either for work,

3 The source of information for 1954 are the orthophotos (volo GAI) that is property of RT-IGM., while information at 2002 are coming from the orthophotos property of the AGEA, namely the Italian Paying Agency, made with the aim to verify the accuracy of farmer's declarations, see http://www502.regione.toscana.it/geoscopio/servizi/wms/OFC.htm 
363 everyday life or leisure reasons, frequent the spots from which that part of landscape could be

364 seen. Thus, while the Visibility provides an analysis of the areas that could more easily be seen,

365 the Frequentation deals with the probability that there are observers on the points from which

366 there is high Visibility, as in the case of noise pollution, where it is not only relevant the level of

367 noise but also the presence of people that could be impacted by it. These percentages are

368 therefore averaged out in order to obtain the total frequentation surface for the entire study

369 region.

370 The criterion Vulnerability indicates the landscape fragility in relation to the socio-territorial

371 context (i.e. productive assets, service industries, urban city, villages, etc.). This element is

372 studied by using two attributes: "Intervisibility" and "Environmental Value". The first attribute,

373 when analysed via GIS, consents to compute and evaluate the Intervisibility within the study

374 area, while the second is connected with the presence and extension of highly important

375 environmental zones such as Sites of Community Importance (SCIs), Sites of Regional

376 Importance (SIRs), Special Protection Areas (SPAs), Oasis, etc. Indeed, planning rules single out

377 these areas, on the basis of previous and ad hoc researches, as important for the habitat and

378 supporting ecosystem services that they are able to provide and for their environmental values.

379 Thus these areas could be considered as an "indirect" indicator of a high environmental value.

380 For each decision alternative represented by the landscape subsystem areas, Saaty's method

381 computes a landscape sensitivity score that is expressed in a 0-3 numeric scale of increasing

382 sensitivity; i.e. $0=$ null, $1=$ low, $2=$ medium, $3=$ high, as shown in Table 1.

383 While in this analysis, due the context that has been analysed, we have supposed that high values

384 and high vulnerabilities tend to be correlated and consequently could be summarized into a

385 synthetic index, in other contexts it could be necessary to have an approach similar to the one 
used for summarising plots suitability and farm resistance to external solicitations. In this case, a

387 table crossing landscape quality levels and vulnerability levels could be built and used to define

388 situations that could be managed with the same approach.

\section{The farm analysis}

389 The analysis at farm level is conducted via a GIS-based multicriteria, as the previous one. This

390 analysis aims to evaluate and map, from a short to a medium period point of view, farmers'

391 likely future strategies adaptation capacity to changes of agricultural policies and resulting

392 strategies (Brunori et al., 2008). This because, after the deep transformation that many

393 agricultural areas of developed countries have gone through since the beginning of the $20^{\text {th }}$

394 Century, a sudden reduction on farming activities could unbalance the landscape and territorial

395 equilibrium. Indeed, the interest for the problems potentially deriving from a sudden reduction

396 on agricultural activities is also apparent from the fact that, since 2006, the original set of IRENA

397 Agri-Environmental Indicators has been reformed by introducing an indicator of the risk of farm

398 abandonment (Corbelle-Rico et al, 2014). While statistics at European level are usually related to

399 administrative units, our analysis goes to a more detailed scale, being based on plots and farm

400 features. The integration of land use and cadastral information has allowed us to use an

401 elementary unit that is very small (plot), while in other researches larger elementary units are

402 used, e.g. a square grid of $1 \mathrm{~km}$ (see, e.g. Piorr et al, 2009). The attribution of each plot to an

403 administrative area, landscape subsystem or other sub-area deemed to be important for a spatial

404 analysis allows the model to reconstruct average values at different spatial scales. An analysis on

405 how the drivers of agricultural land abandonment affect biodiversity and cultural landscapes has

406 been performed on European and non-European case-studies from Beilin et al. (2014). In this

407 paper, due to the specific characteristics of agriculture in the case study area, we have considered 
408 farming abandonment a more threatening process than agricultural intensification. Indeed,

409 according to Agnoletti (2014) both current socio-economic trends, which favour abandonment

410 and industrialization, and conservation policies, which support and promote renaturalisation,

411 may likely cause a loss of critical heritage resources. Besides, a sudden and uncontrolled spread

412 of land abandonment could seriously affect the hydro-geological situation of the case study area,

413 and many other similar ones.

414 In our model we consider farmers choices as affected by two sets of criteria, the first one relating

415 to plots suitability to cultivation, and the second describing farms characteristics; these latter

416 have been classified into the following three subsets (or criteria): a) structural, b) socio-

417 economic, and c) management characteristics. While the first set (plot analysis) aims to analyse

418 the level of plot resistance to abandonment, the second set (farm characteristics analysis) aims to

419 analyse the resistance of farms, that is to say their ability to react to external solicitations. The

420 first criterion (see table 2), namely Plot Suitability to Cultivation, is analysed by the following

421 four attributes: 1) “Exposure”, 2) "Slope”, 3) "Soil texture”, and 4) "Scale/Morphology”. Plot

422 suitability to cultivation differs from the more used concept of land capability in so far it depends

423 from characteristics, such as scale/morphology, that are more influencing farm organization (and

424 costs) than land productivity, while variables like climate (that is deemed to be quite

425 homogeneous at a such small scale) are not taken into account.

426 Criteria, attributes, sub-attributes and scores relating to plot suitability to cultivation are

427 presented in Table 2.

428 Table 2 - Criterion "Plot suitability to cultivation": Attributes, Valuation classes and Scores

\begin{tabular}{|c|c|c|}
\hline Attributes & Valuation classes & Scores \\
\hline \multirow{3}{*}{ Exposure } & SE-SW & 1.00 \\
\hline & NE-SW & 0.80 \\
\hline & SW-NW & 0.80 \\
\hline
\end{tabular}




\begin{tabular}{|c|c|c|}
\hline & NW-NE & 0.60 \\
\hline \multirow{6}{*}{ Slope } & $0 \%-5 \%$ & 1.00 \\
\hline & $5 \%-10 \%$ & 0.95 \\
\hline & $10 \%-15 \%$ & 0.90 \\
\hline & $15 \%-20 \%$ & 0.80 \\
\hline & $20 \%-25 \%$ & 0.70 \\
\hline & $>25 \%$ & 0.20 \\
\hline \multirow{3}{*}{ Soil texture } & loam & 1.00 \\
\hline & sandy & 0.80 \\
\hline & clay & 0.80 \\
\hline \multirow{4}{*}{ Plot Size } & $<0,5$ hectare & 0.85 \\
\hline & $0,5-2$ hectare & 0.90 \\
\hline & 2-5 hectare & 0.95 \\
\hline & $>5$ hectare & 1.00 \\
\hline
\end{tabular}

429 Score: $0=$ better adaptation ability; $1=$ worse adaptation ability

430 Farm Structure (see Table 3.a) is described by means of the following six attributes, 1) "Farm 431 Acreage". "Incidence of Land Rented or on Lease", 2) "Level of Productive Specialization", 3)

432 "Importance of Livestock, Vineyards and Olive Groves", 4) "Agro-tourism services”, 5)

433 "Incidence of Land Rented or on Lease", and 6) "Presence of on farm Agro-food Processing 434 Activities".

435 Table 3.a-Criterion "Farm structural characteristics": Attributes, Valuation classes and

436 Scores

\begin{tabular}{|c|c|c|}
\hline Attributes & Valuation classes & Scores \\
\hline \multirow{4}{*}{ Farmer's age } & $18-40$ & 0.70 \\
\hline & $40-50$ & 1.00 \\
\hline & $60-70$ & 0.80 \\
\hline & $>70$ & 0.40 \\
\hline \multirow{4}{*}{$\begin{array}{l}\text { Rate of hired } \\
\text { workers on total }\end{array}$} & $>60 \%$ total workers & 0.70 \\
\hline & $30-60 \%$ total workers & 1.00 \\
\hline & $1-30 \%$ total workers & 0.80 \\
\hline & none & 0.40 \\
\hline \multirow{2}{*}{$\begin{array}{l}\text { Tie between } \\
\text { family and farm }\end{array}$} & high & 0.60 \\
\hline & medium & 0.70 \\
\hline
\end{tabular}




\begin{tabular}{lll} 
& low & 0.80 \\
\hline \multirow{2}{*}{$\begin{array}{ll}\text { Generational } \\
\text { turn-over }\end{array}$} & possible (there are identified successors) & 0.50 \\
& not possible (there are not successors) & 1.00 \\
& uncertain (there are successors, but not interested in farming) & 0.80 \\
\hline Ability to & high & 0.60 \\
networking in & medium & 0.70 \\
business & low & 0.90 \\
\hline
\end{tabular}

Score: 0 = better adaptation ability; $1=$ worse adaptation ability

437 The criterion describing Socio-economic Characteristics (see Table 3.b) includes five attributes:

438 1) “Age of the Farmer", 2) "Presence of Regular Hired Workers", 3 ) "Farmer's Family Ties with

439 the Farm”, 4) “Generational Turnover (presence of a possible farming successor)”, and 5)

440 "Networking Capacity".

441 Table 3.b-Criterion "Farm socio-economic characteristics": Attributes, Valuation classes and

442 Scores

\begin{tabular}{llc}
\hline Attributes & Valuation classes & Scores \\
\hline Cropping & conventional or low input & 1.00 \\
techniques & organic & 0.80 \\
\hline \multirow{2}{*}{$\begin{array}{l}\text { Level of } \\
\text { mechanization }\end{array}$} & uses only own machineries & 0.40 \\
outsourcing & harvesting hired service & 0.60 \\
& only hired services for machinery & 0.80 \\
\hline \multirow{2}{*}{ Incidence of } & CAP aid on total revenue > 60\% & 1.00 \\
CAP aid & CAP aid 26-60\% of total revenue & 1.00 \\
& CAP aid <25\% of total revenue & 0.85 \\
& direct sale to final consumer & 0.70 \\
\hline \multirow{3}{*}{ Market channels } & prevalent sale to retailers & 0.60 \\
& produce to co-op or associations & 0.80 \\
& prevalent sale to wholesalers & 0.90 \\
\hline
\end{tabular}

443 Score: $0=$ better adaptation ability; $1=$ worse adaptation ability

444 Farm Management Characteristics (see Table 3.c) are measured through four attributes: 1)

445 "Cultivation Techniques (Conventional, Integrated, and Organic farming Techniques)" 2) Level 
446 of Mechanization Outsourcing (hiring contractors)", 3) "Incidence of CAP direct payments on

447 Total Revenue", "and 4) "Main Selling Channels".

448 Table 3.c-Criterion "Farm management characteristics": Attributes, Valuation classes and

449 Scores

\begin{tabular}{llc}
\hline Attributes & Valuation classes & Scores \\
\hline & $0-5$ hectares & 0.70 \\
& $5-25$ hectares & 1.00 \\
Farm acreage & 25-60 hectares & 0.80 \\
& $60-100$ hectares & 0.40 \\
& 100-200 hectares & 0.20 \\
& $>$ 200 hectares & 0.40 \\
\hline Level of & high (only cereals) & 1.00 \\
specialization of & medium (50\% cereals - 50\% grassland) & 0.80 \\
arable land & low (grassland for hay and grazing $>50 \%)$ & 1.00 \\
\hline Importance of & high importance (specialization) & 0.60 \\
livestock, & medium importance & 0.80 \\
vineyards, olive & low importance (income integration) & 0.90 \\
groves & absence & 1.00 \\
\hline \multirow{2}{*}{ Agritourism } & Presence & 0.50 \\
& Absence & 1.00 \\
\hline \multirow{2}{*}{ Share of rented or } & high $(>80 \%)$ & 1.00 \\
leased land on & medium $(50-80 \%)$ & 0.80 \\
total land & low $(10-50 \%)$ & 0.70 \\
& very low (<10\%) & 0.60 \\
\hline \multirow{2}{*}{ Small-scale food } & presence of both wineries and small food processing plants & 0.60 \\
etc. processing & presence only of wineries & 0.70 \\
plants & presence only of small food processing plants & 0.80 \\
& absence both of wineries and small food processing plants & 1.00 \\
\hline
\end{tabular}

450 Score: $0=$ better adaptation ability; $1=$ worse adaptation ability

451 The three criteria relating to Farm features consent to evaluate Farm ability to react to external

452 solicitations such as change in market trends or in policy context.

453 As in the case of the territorial analysis, the farm analysis is carried out via a Geographic

454 Analytical Hierarchical Process, based on two spatial elementary units, namely plots and farms, 
455 to represent the geographical decision alternatives to be ordered and evaluated. Indeed, while

456 most of the studies dealing with land use focus on plot of land with homogeneous characteristics,

457 changing in land use are very often influenced by the characteristics of the farms they belong to.

458 Consequently, while the current description of the land use in a territory could be based only on

459 territorial units such as plots, changes in land use due to socio-economic drivers have to take into

460 account also the farm level. This problem has been stressed also by Brady et al. (2009), who

461 perform an analysis of the potential impacts of decoupled agricultural support on farm structure,

462 biodiversity and landscape mosaic in a sample of EU Regions by using a spatial agent-based

463 model called AgriPoliS. While Brady et al. use a mathematical simulation model, our model is

464 more qualitative, but allows us to include into our analysis the results of the participative

465 approach and to take into account landscape elements that are not strictly linked to the

466 agricultural landscape mosaic. Nevertheless, these models have some common features insofar

467 that both consider dynamics and space, the relevance of farmers decisions and they work at a

468 high spatial resolution (i.e. plot/field). In our farm analysis, the Saaty's decomposition phase

469 provides two different hierarchical structures: in the first, the goal is represented by plots

470 suitability to cultivation and the consequent risk of abandonment, while in the second the goal is

471 to evaluate farms reaction to external solicitations on the base of their socio-economic, structural

472 and management characteristics, which have also an impact on the risk of land abandonment. An

473 important step of the entire evaluation process is the participatory phase; the definition of criteria

474 and attributes, as well as the weights computation are all based on the information acquired both

475 via interviews and via focus-groups with local stakeholders. For this reason, as in the case of the

476 territorial analysis, the methodology described (attributes, scores, etc.) is partly depending on the

477 feature of the case-study area. Once that the hierarchical structures have been defined, the 
comparisons between pairs of the constituent elements (criteria and attributes) are performed in

479 accordance with the Saaty's semantic scale (Saaty, 1980). Finally, the measurement of scores for

480 each geographic alternative, as regards to each criterion, is developed in two steps: firstly the

481 alternatives are ordered in conformity with a 0 to 1 scale where 1 indicates the maximum farm

482 flexibility in relation to external changes and 0 the minimum flexibility; then these values are

483 rescaled in a 1 to 5 scale in order to facilitate the discussion with the stakeholders (see figure $5 \mathrm{a}$

484 and 5 b, relating to the case study analysis). Both in the case of plots and farm features analyses,

485 the results of the hierarchical re-composition stage should be validated by stakeholders through a

486 discussion about the effective meaning and the territorial consequences of the obtained values.

487 As in the previously described analyses, the criteria and attributes could be integrated to take into

488 account other features, e.g. geographical location as regards accessibility. The study of

489 infrastructure interconnecting farm plots and farms with the territory they are located in, asks for

490 an analysis taking into account both the amount of roads, but also their level of

491 quality/maintenance. Besides, in rural areas sometimes seclusion and "privacy", at least from a

492 touristic viewpoint, is seen as a positive factor and not as a negative one. Thus in some cases the

493 amount of efforts to properly measure this characteristic could be too high to justify its

494 consideration. This is the case, in the Authors opinion, of the case-study area.

495 The final values of each geographical alternative category (plots and farms) are then parted into

496 three classes (low, medium, high), which were necessary for the construction of a fuzzy

497 membership function. In accordance with fuzzy logic (Boroushaki and Malczewski, 2010;

498 Karsak, 2004; Sangalli, 1998) the probability of each alternative to belong to each class (low,

499 medium, and high) is computed for both plots and farms spatial units, as in the following figure

5002 , which refers to the case-study analysis. 

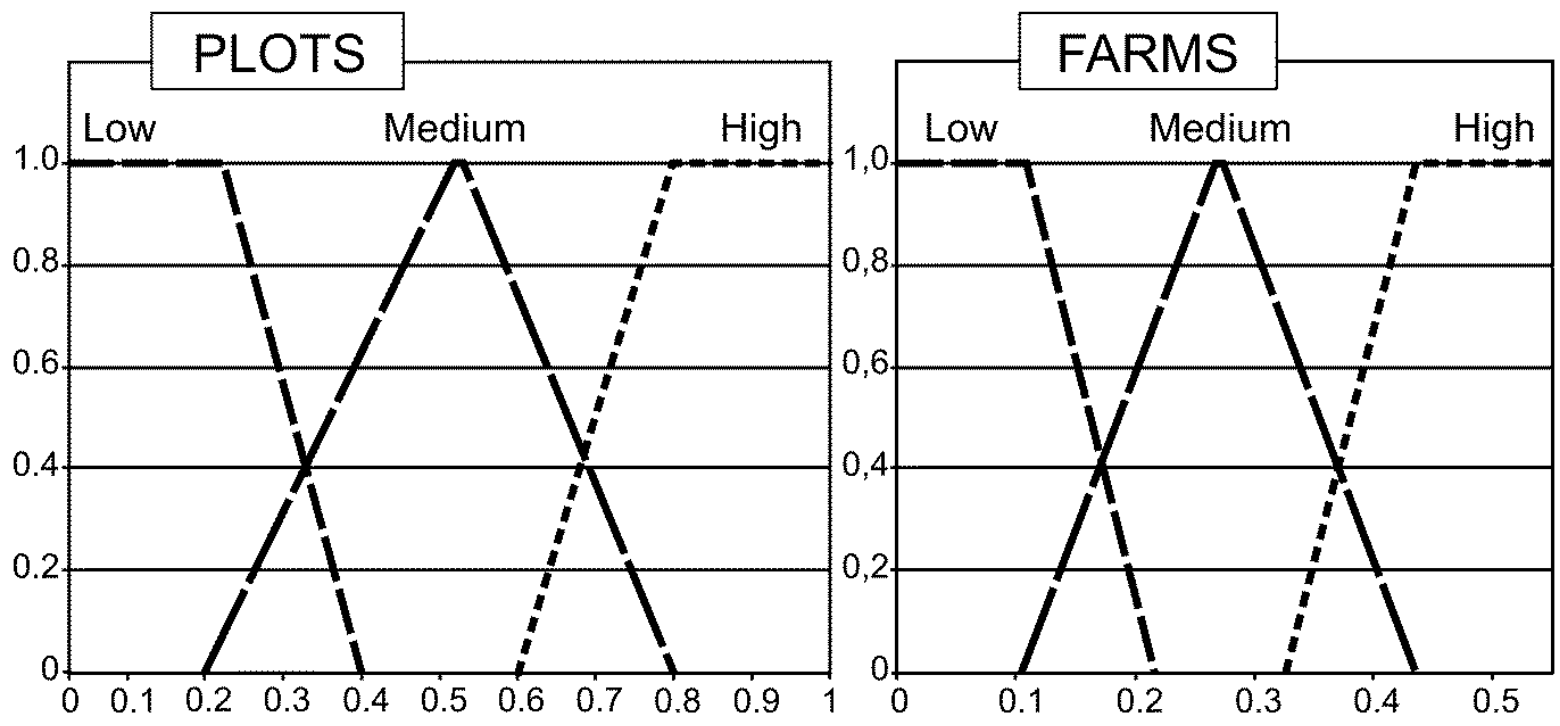

502 Figure 2. Fuzzy membership function for plots and farms.

503 In figure 2 the three lines represent the membership function relating the numeric scale (on the $\mathrm{x}$ -

504 axis) and the linguistic scale "low-medium-high". The lines shows that, e.g., while for a score of

5050.1 in the plot analysis the probability to belong to the class "low" suitability to cultivation is

$506100 \%$ (probability is measured on the y-axis), in the case of 0.3 , due to fuzziness, the value could

507 belong both to "low" and "medium" classes, but with a different level of probability.

508 Then, a cross-reading phase is carried out via a fuzzy logic in order to compare and integrate the

509 synthetic index measuring farms reaction to external solicitations with the one summarizing plots

510 suitability to cultivation. In this phase, a set of farm evolutionary paths/strategies are

511 individuated on the base of farms adaptation capacity, that is to say their ability to survive as

512 viable enterprises, and each combination deriving from crossing the classes ( $\mathrm{L}, \mathrm{M}$, and $\mathrm{H})$ of

513 plots and farms is assigned to one of the defined evolutionary paths in accordance with the

514 maximum probability value. The definition of farm strategies and the relation with the classes

515 combining plot and farm resistance are, in part, area specific and consequently, the classification

516 may need to be slightly adapted when analysing an area with different features. The following 
517 table 4 presents - as an example - the results of this phase for the case study analysis. Nine fuzzy

518 rules have been identified for the case study; these rules enable to determine, for both plots and

519 farms, the probability to belong to one of the seven classes:

520 1. Very High (VH),

521 2. High $(\mathrm{H})$,

522 3. Medium to High (MH),

523 4. Medium (M),

524 5. Low to Medium (LM),

525 6. Low (L), and

5267 . Very Low (VL).

527 Indeed, the elements belonging to some of the nine classes (coming from the crossing of the

528 three levels plot analysis and the three levels farm analysis; 9 fuzzy rules are needed for defining

529 these classes) are too similar to give origin to separate evolutionary paths (evolutionary paths are

530 only seven), also due to problems of uncertainty in scores and weights attribution during the

531 Multicriteria analysis. Table 4 presents, as an example, the final seven classes of farms

532 evolutionary paths and their relation with the crossing of farm and plot analyses related to the

533 case study that will be described in the next section. For each combination of plot-farm the final

534 membership class (from VH to VL) is assigned in accordance with the maximum probability 535 value.

536 Table 4. Fuzzy classes defining farm evolutionary paths for the case study according to their

537 adaptation capacity.

\begin{tabular}{lll}
\hline \multicolumn{3}{c}{ Plot "resistance" or suitability to cultivation } \\
\hline $\operatorname{High}(H)$ & $\operatorname{Medium}(M)$ & $\operatorname{Low}(L)$ \\
\hline
\end{tabular}




\begin{tabular}{lcccc}
\hline Farm & $\begin{array}{c}\text { High } \\
(\mathbf{H})\end{array}$ & $\begin{array}{c}\mathbf{V H} \\
\text { maintenance }\end{array}$ & $\begin{array}{c}\mathbf{H} \\
\text { maintenance } \\
\text { multifunctionality }\end{array}$ & $\begin{array}{c}\mathbf{M H} \\
\text { multifunctionality }\end{array}$ \\
\cline { 2 - 5 } $\begin{array}{l}\text { or reaction } \\
\text { capacity to } \\
\text { external } \\
\text { solicitations }\end{array}$ & $\begin{array}{c}\text { Medium } \\
(\boldsymbol{M})\end{array}$ & & $\mathbf{M}$ uncertain strategies & \\
\cline { 2 - 5 } & Low $(\boldsymbol{L})$ & $\begin{array}{c}\mathbf{L M} \\
\text { transfer to } \\
\text { strongerfarms }\end{array}$ & $\begin{array}{c}\mathbf{L} \\
\text { transfer to stronger } \\
\text { farms/abandonment }\end{array}$ & $\begin{array}{c}\text { VL } \\
\text { abandonment }\end{array}$ \\
\hline
\end{tabular}

538

539

540 541 evolutionary paths:

542

543

544

545

546

547

548

549

550

551

552

553

554

555

556 structure. resources.

Level of adaptation capacity: $\mathrm{VH}=$ very high, $\mathrm{H}=$ high, $\mathrm{MH}=$ medium-high, $\mathrm{M}=$ =medium,

LM=medium-low, $\mathrm{L}=$ low, $\mathrm{VL}=$ very low.

The seven fuzzy classes shown in Table 4 relate to the following farmers' strategies and farms

1. The class VH includes farms characterized by a high adaptation capacity and by plots with on average a high suitability to cultivation. These farms will very likely maintain their present cultivation systems without relevant changes in their organizational

2. The class H represents farms whose evolution may vary from the present status maintenance to an increase of multifunctionality $(\mathrm{MH})$; they represent an optimal situation as any of these developments will increase both the agricultural and the landscape value.

3. The class $\mathrm{MH}$ represents farms with a high capability of adaptation to the external changes, with plots that have a low suitability to agricultural use. The evolution of these farms is almost inevitably directed to multifunctional agriculture (i.e. farm holidays, educational farms, eno-gastronomic tourism, etc.) or, alternatively, to the creation of value-added products; otherwise the low suitability to agricultural use could cause land abandonment with negative repercussions on both environmental and landscape 


\section{to provide public decision makers with operative guidelines.}

\subsection{The identification of the priorities and actions}

574 The last phase of our study combines the results of the territorial analysis (where areas are 575

4. The class M is typical of farms with an intermediate and uncertain evolution since their farmers may adopt strategies that vary from the maintenance of the present status $(\mathrm{H})$ to the land abandonment (VL) or sale of some plots (LM), as well as from multifunctionality (MH).

5. The class LM includes farms with low adaptation capacity and whose plots have a high suitability to cultivation. The weak organizational structure of such firms and the high pressure of land demand will likely determine the cessation of these agricultural enterprises in the medium term. However, in this case, land will probably be acquired (rent, sale) and cultivated by other farmers.

6. The class L includes farms whose evolution may vary from land abandonment (VL) to sale of plots to stronger farms (LM).

7. The class VL is characterized by farms with low adaptation capacity and plots that, on average, have a low suitability to cultivation. These are the weakest farms, which will probably abandon all agricultural activities in the medium term, unless some supporting actions cause a rupture and a deep change of the farm development path.

Such crossover study is fundamental to be able to foresee farmers' strategies and behaviours and The last phase of our study combines the results of the teritorial analysis (where areas are classified on the base of their level of landscape sensitivity) with the ones of farm analysis (where farms strategies and evolutionary paths are analysed). At this stage, the territory is parted into homogeneous areas, for which - after defining priorities with stakeholders - some ad hoc response actions are identified, in accordance both with their specific landscape sensitivity and 
peculiarity and the expected farm evolution. Priorities and actions should take into account not

580 only the results of the analysis but also the institutional and cultural context of the area. In a very

581 simplified scheme, we could individuate the following four situations:

582 - High landscape value and high farm adaptability. Landscape has a high value and farms

583 are viable having a good adaptation capacity to external changes; in this case public

584 actions aiming to promote the territory could be sufficient to guarantee a sustainable

$585 \quad$ landscape;

$586 \quad$ - High landscape value and low farm adaptability. Landscape has currently a high value

587 but there is the risk that a diffuse abandonment of agricultural activities undermines the

588 present situation. In this case incentives aiming to maintain agriculture activities and to

589 promote an entrepreneurial "cultural change" are needed;

590 - Low landscape value and high farm adaptability. In this case the economic viability of

591 agricultural and rural activities are not at risk, but the quality of landscape should be

592 improved through ad hoc interventions;

$593 \quad$ - Low landscape value and low farm adaptability. In this case both landscape quality and

594 the viability of the agricultural economic fabric are in bad conditions; consequently both

595 actions aiming to improve quality of landscape and incentives to maintain agricultural

$596 \quad$ activities are needed.

597 Incentives should give preference to the groups of farmers that have a positive attitude towards

598 multifunctionality and promote a cultural change able to improve the awareness of the important

599 role that proper agricultural activities could play in the maintenance/improvement of the

600 landscape quality level. 
601 Response actions should take into account local stakeholders' point of view and be truly shared

602 by the local community, since this usually makes policies towards a sustainable rural landscape

603 more effective than bottom-up ones.

604 3. The case study: an overview of area characteristics the and results of the applied 605 methodology

606 This chapter presents the results of a first, simplified application of our model, aiming to verify

607 its validity. Due to the complexity of the analyses required by our governance model and to the

608 specific features of the case study areas, we have decided to focus the analysis at territorial level

609 on the issue of landscape sensitivity. This also because the agriculture of the case-study area is

610 mainly related to winter cereals and grassland, with extensive livestock breeding, and has a great

611 share of land that is managed accordingly to organic farming or integrated farming rules, thus

612 reducing - in comparison with more intensive agricultural areas - the importance of ecosystem

613 services related to environment and regulating functions. Contrariwise, its iconic landscape is

614 very well-known both at national and international level and deserves special attention. Local

615 population is aware of it and it is willing to preserve the actual quality level of landscape from

616 further negative transformation. A further simplification that has been adopted for the case study

617 relates to the spatial elementary units for the territorial analysis, as detailed in the relative

618 section. The present chapter is organized as follow. First of all, a brief description of the study

619 area and its features are given. Secondly, more information are given on how the participative 
620 approach has been implemented during the case-study analysis. Then, results are given for the

621 analyses that have followed the lines described in the previous chapter

622 3.1. The study area - main characteristics

623 The study area chosen for validating the model is the territory of Castiglione d'Orcia (Siena, 624 Italy), one of the five municipalities (Castiglione d'Orcia, Montalcino, Pienza, Radicofani and

625 San Quirico d'Orcia) belonging to the Orcia Valley, a Tuscany hilly area that, during the last

626 decades, has been affected by deep changes in landscape due to farmers' adaptation both to

627 market trends and to agricultural policies.

628 The territory has a strong rural character with several organic and holiday farms. While, as in the

629 rest of Italy, most of the farms have an acreage below 10 hectares, the share of land accounted by

630 medium and large farms is prevalent. All the municipalities of Orcia Valley are characterized by

631 the presence of urban structures and architectonic furniture dating back to the medieval and

632 Renaissance age. Other distinctive elements of the area are fortified villages, scattered rural and

633 religious buildings set in a territory characterized by the presence of:

634 - Erosive forms (erosion furrow, named "biancane" or badlands) with a typical flora

635 (Maccherini et al., 1998);

636 - Large fields where only durum wheat and forage are cultivated;

637 - Small extension of woodlands, usually located in areas with strong-steep slope;

638 - Isolated or small groups of monumental trees;

639 - Canyon and wide riverbeds of Orcia River with typical riparian vegetation giving a

640 characteristic aspect and an ecological value to the landscape.

641 In July 2004, UNESCO has recognized the Orcia Valley as humanity cultural heritage in

642 accordance with the Criteria IV and VI (UNESCO, 1972). This because this "landscape is part of 
643 the hinterland of Siena, redrawn and developed when it was integrated in the territory of the city-

644 state in the fourteenth and fifteenth century to reflect an idealized model of good governance and

645 to create an aesthetical picturesque landscape. The landscape's aesthetics inspired many artists,

646 whose images have come to exemplify the beauty of well-managed Renaissance agricultural

647 landscapes. This agrarian and pastoral landscape reflects an innovative land-management

648 system" (Rössler, 2010). Although the distinctive and appreciated features above described are

649 still present, albeit sometimes with a much smaller extension (e.g. in the case of "biancane"), the

650 current landscape of Val d'Orcia is very different from the one of those centuries (Phillips, 1998,

651 Marignani et al., 2008). Indeed, current landscape, with its distinctive feature of having a

652 different color in each season, is very much appreciated, and it is often present in gadgets, such

653 as calendars with pictures of Tuscany rural landscapes. An analysis of the processes and actors,

654 both local and extra-local, who have contribute to the emergence of Val d'Orcia as an iconic

655 landscape is provided by Gaggio (2014). Although, on the one hand, the Orcia Valley has

656 acquired a strong identity that has by now assumed the role of an economic resource thanks to a

657 unique combination of natural and anthropic elements, on the other hand the agricultural activity

658 presents signs of environmental weakness due to the presence of sites with a high ecological

659 value and areas very important from a historic-cultural and architectural viewpoint. Pictures of

660 Val d'Orcia landscape may be found on the Tuscany Region Atlas of Rural Landscapes ${ }^{4}$ and on

661 many sites related to Tuscany landscape and tourism.

662 According Agricultural Census data at 2010 (ISTAT, 2010) the Municipality of Castiglione

663 d'Orcia, whose territory has been used for the case-study analysis, is characterized by:

4 http://www.regione.toscana.it/documents/10180/70960/ATLANTE\%20DEI\%20PAESAGGI\%20TOSC ANI\%20val\%20d'orcia/69995032-581b-46fe-b856-8a4b4b20ecf9 
- a high share of Utilized Agricultural Area (UAA) on Total Agricultural Area (77,5\%) and, consequently, a low share of Woodlands on Total Agricultural Area (15,6\%);

- a high share of Arable lands on UAA (80,0\%)

667

- a share of about $9-10 \%$ of both Olive groves and Permanent grassland on UAA, while Vineyards account only for about $1 \%$.

669

Indeed, Val d'Orcia is quite heterogeneous from this point of view since the Municipality of

670 Montalcino, e.g., presents a higher presence of Woodlands $(40,7 \%)$ and consequently a lower

671 share of UAA $(50,0 \%)$, a lower share of arable lands $(49,1 \%)$ and a very high share of vineyards

$672(37,3 \%)$. In this case, the specialization towards vineyards and the consequent simplification of

673 landscape is seen as a threat, while in the case of Castiglione d'Orcia this simplification (one

674 season, one colour) is appreciated.

675 Breakdown data related to arable land is available only for farms that have all their land inside

676 the municipality (ISTAT, 2010), that in the case of Castiglione d'Orcia account for about $69 \%$ of

677 the total arable area. In these farms, arable land is mainly dedicated to Cereals (usually winter

678 cereals) that account for 45,2\%, non-permanent Grassland (25,7\%) and Fallow land (23,9\%).

679 According to an annual survey of the Italian Institute for Statistics (ISTAT 5 ), trends at national

680 level seems to show an increase of fallow land, especially in the Regions of Central Italy, such as

681 Tuscany. Although land could be kept fallow also for agronomic reasons, such a high share

682 could also imply a low profitability of cropping that could bring about land abandonment due to

683 economic conditions.

${ }_{5}$ Source: annual survey on "Early estimates for crops" (Indagine sulle intenzioni di semina degli agricoltori), agricultural campaigns from 2011-2012 to 2014-2015 http://www.istat.it/it/istituto-nazionaledi-statistica 
684 According to Lorenzini (2011) Val d'Orcia is one of the Italian "peripheral areas of low

685 demographic density, which in the 1970s have been subject to a progressive depopulation and

686 abandonment of the agricultural activities, but where this trend has been inverted by the

687 implementation of a strategy of valorization of culture-based goods and services linked to the

688 local history or the traditional local savoir faire". For these reasons Lorenzini classifies Val

689 d'Orcia as a Extra-Urban Cultural District, characterized by a "high integration, both horizontal

690 and vertical, of the cultural industries with the other productive sectors of the area". Among

691 these activities, in the agricultural sectors, there are certified (origin denomination or organic)

692 products and agro-tourism. Indeed, while the Municipality of Castiglione d'Orcia had at 2011 a

693 Resident Population of 2453 inhabitants (ISTAT, 2011), in 2013 the number of overnight stays

694 was higher than 20000 and 2014 provisional data shows a slight increase. . On the five

695 Municipalities of Val d'Orcia, whose population was 13570 inhabitants at 2011, the amount of

696 overnight stays in 2013 was higher than 125500 . From this overnight stays $50 \%$ are accounted by

697 foreigners in the case of Castiglione d'Orcia, while in Orcia Valley the share was of about $61 \%$.

698 Although present and past foreign tourism has had a deep influx in the development of the area

699 and its landscape, according to Gaggio (2011) "rural Tuscans have chosen to bear testimony to a

700 disappearing civilization, imagining themselves as its heirs and stewards, but they have not done

701 so merely to please the tourists. In a sense, the peasant civilization imagined (or believed to be

702 true) by contemporary Tuscans is no more historically "accurate" than that imagined (or believed

703 to be true) by tourists, and the same holds for the landscape that the former have built and the

704 latter come to visit". Besides, the relations between the iconicity and branding of landscape and

705 the inclusion of Val d'Orcia in a global context had some consequences also on the shaping of

${ }_{6}$ Source: ISTAT - Census of population at 2011; Siena Province: Statistical data on Tourism 
agricultural landscape, e.g. although "Villa Banfi" has contributed to the growing reputation

707 abroad of "Brunello di Montalcino" and the landscape it comes from, nevertheless it is assumed

708 to have caused negative effects on shaping this same landscape, due the increasing specialization

709 in vineyards and consequent simplification of landscape caused by economic reasons (Mopurgo,

710 A., 2005).

\section{3.2. The participative approach in the case-study analysis}

712 In this paragraph we give a brief summary of the participative approach in the analysis of

713 Castiglione d'Orcia case-study. Two different tools were mainly utilized:

714 a) Individual interviews to key informants, based on a questionnaire with open answer. Key

715 informants were represented by different types of farmers, local residents, representatives

716 of associations and other groups of stakeholders. Interviews have been mainly used to

717 gather information for the analyses, such as attribute and sub-attribute to be considered

$718 \quad$ and their scores;

719 b) Two focus groups. The first one has involved stakeholders - such as representatives of associations dealing with trade and shop-keeping, tourism, environment, hunting, etc. -

721 whom, for various reasons, are interested in using the environmental resources of the territory under analysis. In this case the aim was to gather information from all the stakeholders which, for different reasons, could be involved in landscape governance. The second one has involved farmers, since they are the main actors in changing agricultural landscape and it is important to understand both their attitude towards its evolution and the different strategies that farmers would implement depending on the trends of market conditions and law and policy context. In this case, farmers have been chosen in such a way as to be representative of different types as regards farm acreage 
(small - large farms), employed techniques (conventional, low input, organic), etc. This in the belief that not only economic reason (e.g. related to farm acreage) but also

\subsection{The results of the evolutionary, landscape and farm analyses}

\section{The evolutionary analysis}

\section{5}

As we have already pointed out in the description of the general framework model, the historical evolutionary phase requires an accurate investigation on both public and private archives, with

747 information are successively controlled, processed and then integrated and validated by

748 interviews, made i.e. to farmers, local associations, community members and people representing

749 the categories involved with the territory under study.

750 The current structure of Val d'Orcia landscape, which is characterized by large hills with

751 extensive cultivations, is the result of the deep transformation that, starting from sixties of 20th 
752 Century (Phillips, 1998; Rossi and Vos, 1993, Marignani et al. 2008), has involved the

753 agriculture of this area as well as that of a large part of Tuscany hills (Rovai, 1994). This

754 transformation is due to three principal driving forces $(003,2012$ masked for blind review; Neri 755 et al., 2008).

756 - The introduction of supplementary payments for durum wheat in the CAP regime

757 (Council of European Communities, 1976) made this cultivation extremely attractive 758 from an economic viewpoint, also because there are no valuable alternatives;

759 - The technological development consequent to:

$760 \quad \circ \quad$ A high diffusion of mechanization, particularly promoted by credit policies,

- The introduction of new durum wheat varieties, characterized by higher

762 productivity, shorter size and higher lodging resistance.

763

764

765

766

767

768

769

770

771 These transformations have caused the present landscape configuration that has made Orcia

772 Valley famous and easily identified all over the world for aesthetic reasons (i.e. one colour for

773 each season). 
774 Figure 3 shows the empirical evidence of this transformation that produced a clear simplification

775 and an increasingly anthropic aspect of the Orcia Valley landscape. Where in 1977 were present

776 little arable plots interrupted by natural corridors (hedges, drainage ditches, etc.), in 1994 the

777 natural areas had completely disappeared and only a large arable hilly plot remained. Another

778 similar situation can be individuated by comparing the two maps: while in 1977 there was a

779 mixed plot (arable land with scattered trees), in 1994 the same plot was completely converted to

780 a bare arable soil.

781
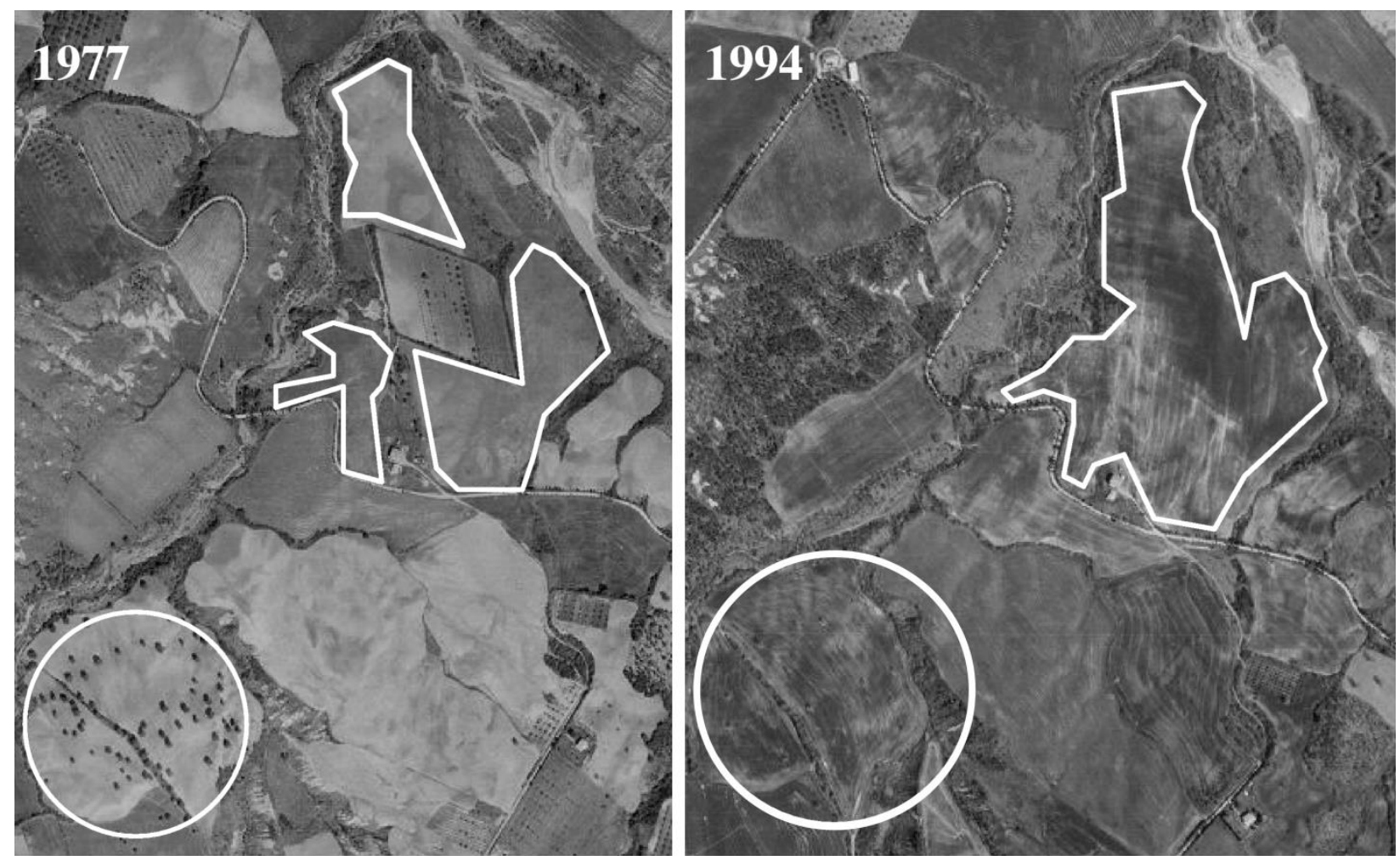

782 Figure 3. Aerial photos, whose comparison highlights Orcia Valley landscape modifications.

783 Source Ortophoto cartographies from the Italian Military Geographic Institute

784 The landscape analysis

785 The territorial analysis for the case study, as already anticipated, has been focused on landscape

786 sensitivity and performed using landscape systems and subsystems as spatial elementary units.

787 This choice represents a simplified approach since these units have been defined "outside the 
788

789

790

791

792

793

794

795

796

797

798

799

800

801

802

803

804

805

806

807

808 809 case-study area and highlights the most sensitive areas that need special attention in territorial 810 planning process, i.e., the System of Pliocene hills - Subsystem of Orcia and Paglia valley, and,

model". Although the use of these pre-defined units could be justified since they are recognized in official planning, in a more detailed and comprehensive analysis, or in a governance model built for an integration of tools relating to planning and sectoral policies, the individuation of homogeneous spatial units should be based on the results of the model itself. Indeed, different landscape system and sub-system have often different planning constraints and rules; for this reason, in this first and simplified application of our governance model, we have considered this classification as relevant, although it could have been possible, through the data gathered and analysed in the present paper, to hypothesize a different classification of the territory under study.

According to (Rossi et al, 1994), the case study area included two landscape systems and five landscape subsystems. The subsystems were the following: System of Pliocene hills - Subsystem of low Orcia valley (CP13), System of Pliocene hills - Subsystem of Arbia and Asso valley (CP8), System of Pliocene hills - Subsystem of Orcia and Paglia valleys (CP9), System of Antiappennine Range - Subsystem of Amiata Mountain (RA11), System of Antiappennine Range - Subsystem of Montalcino and Castiglione d'Orcia Mountain (RA8). Landscape systems are in fact quite ample ambits in which landscape characteristics may vary; for this reason they are detailed into different landscape subsystems. In more recent times, this classification has been slightly changed in the framework of the implementation of the Tuscany Region legislation on territorial government (Regione Toscana, Law 65/2014 and the "Piano Paesaggistico", i.e.

807 Landscape Plan of Tuscany - Regional Council Resolution 37/2015).

808 The cartographic hierarchical tree (Figure 4) shows the results of the territorial analysis for the 
811 in a lower degree, the System of Antiappennine Range - Subsystem of Amiata Mountain and the

812 System of Antiappennine Range - Subsystem of Montalcino and Castiglione d'Orcia Mountains.

813 They all have medium-high landscape sensitivity while the other subsystems present a low value.

814 In general the landscape sensitivity value within the study area is included in a range which

815 varies from 0.69 to 2.48 and then from low to medium-high in accordance with the adopted (0-3)

816 scale. The Orcia and Paglia valley subsystem is the most critical one and this is due to its high

817 score for the intrinsic value criterion, resulting from an elevated frequentation, a significant

818 persistence of landscape elements and a high Visibility. The important presence in this sub-

819 system of areas that are relevant from an environmental viewpoint also contributes to increase its 820 sensitivity value.

821

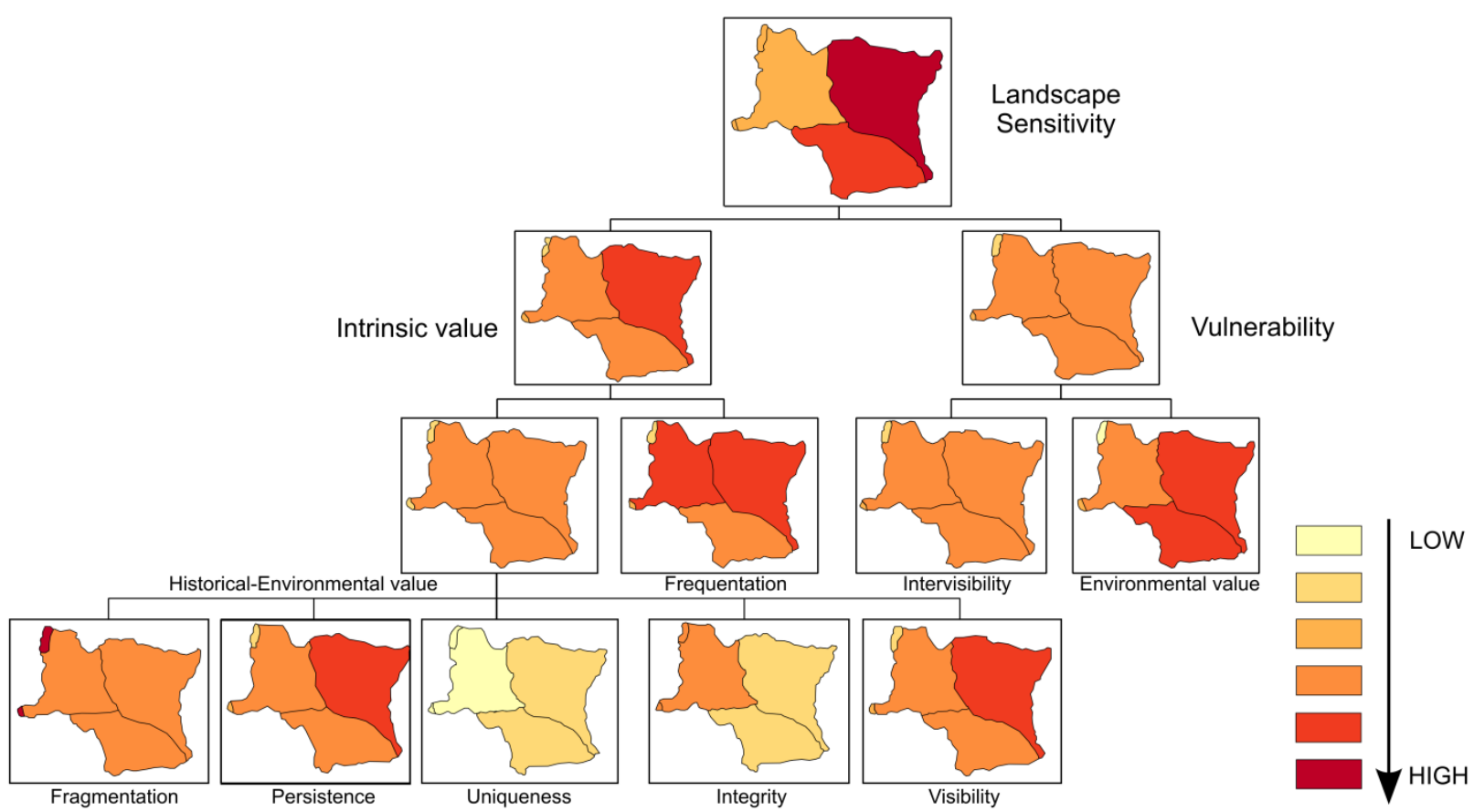

822 Figure 4. The cartographic hierarchical tree relating to the measure of Landscape sensitivity in Orcia Valley study area. 


\section{The Farm analysis}

825 As described above, when giving the general outline of the adopted methodology, farm analysis

826 has been performed by measuring the criterion relating to Plot Suitability to Cultivation and the

827 ones relating to Structural, Socio-economic, and Management characteristics of farms. These

828 criteria are described and measured by several attributes, which have been described in Tables 2

829 and 3.a, 3.b and 3.c in the previous chapter.

830 For the present research, 199 farms were analysed and their structural and socio-economic

831 profiles were assessed. Such farms accounted in total for an area of 5637 hectares of cultivated

832 land, nearly corresponding to the $60 \%$ of the total municipality utilised agricultural area (UAA).

833 As above stated, the aim of farm analysis is to determine both plots natural suitability to

834 cultivation and farmers' adaptation capacity to external changes in accordance with socio-

835 economic, structural and management characteristics of their farms.

836

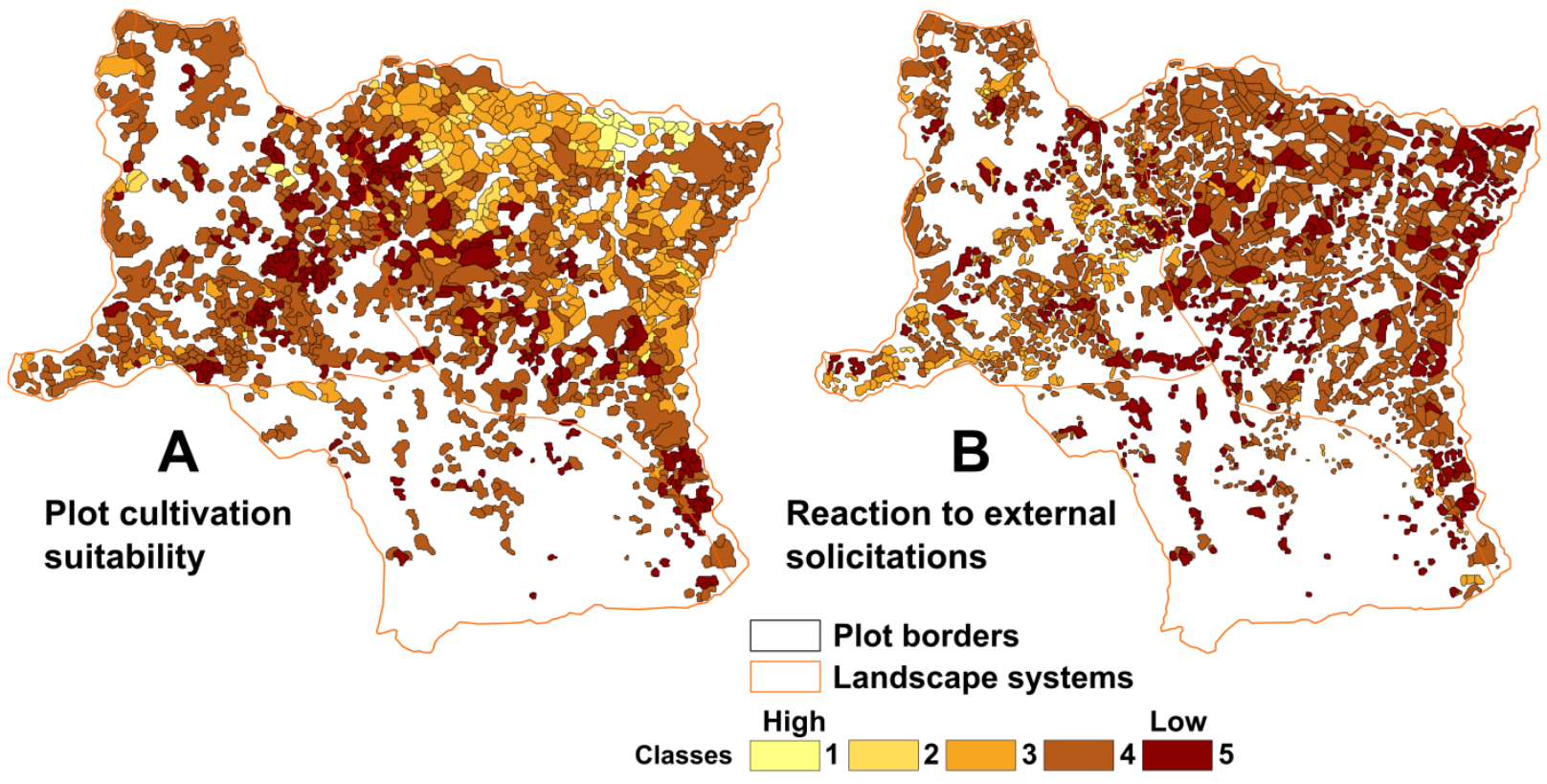

837 Figure 5. Results of the analyses at farm level a) plot's suitability to cultivation, b) farm's

838 capacity to react to external solicitations, $1=$ highest level, $5=$ lowest level. 
839 As already anticipated, the discussion with stakeholders have been made on the base of a scale

840 from 1 to 5 in order to facilitate it. Figure $5 \mathrm{a}$ and $5 \mathrm{~b}$ shows this five classes representation both

841 for the criteria relating to Plot suitability to cultivation and Farm adaptation capacity.

842 Then, the final values of each geographical alternative category (plots and farm) have been

843 parted into three classes (low, medium, high), which have been used to construct the fuzzy

844 membership function already shown as an example in chapter 2 (figure 2).

845 The plot level analysis highlighted that over a quarter of the cultivated land (27\%) presents a

846 relatively scarce suitability to cultivation and, consequently, that there is the risk of abandonment

847 in case of reduction of durum wheat prices or of EU subsidies. On the contrary, the remaining

848 part of the study area has a good suitability to cultivation that would enable farmers to maintain

849 adequate profitability levels even in case of a worsening of the economic situation due to

850 external variables. This part of the area is mainly located in the northern part of the study region,

851 close to the Orcia River, and it is characterized by a gentler slope.

852 Farm level analysis results highlight that about the $70 \%$ of the assessed farms have a high level

853 of adaptive capacity to external changes, whereas the remaining $30 \%$ present a reduced

854 adaptation capacity; this latter might cause the abandonment of some of the cultivated plots and

855 even the cessation of farming if external conditions become exceedingly adverse. According to

856 the results of interview and focus groups, a significant factor affecting strategies of farms is

857 related to their territorial extension and morphology. Indeed, small and medium size farms seem

858 to have a higher external changes adaptation capacity when compared with larger ones, these

859 latter being more rigid in relation to cost structure (i.e. hired farm workers, purchase of external

860 services, etc.) and consequently more fragile in case of market turbulence. The socio-economic

861 analysis indicates that the agricultural productive system of the area is quite resistant, even 
862 though a deterioration of market conditions might have a high impact on environmental variables

863 and subsequently on landscape configuration.

864 From the crossing of farm and plot resistance level, seven farms evolutionary paths have been

865 individuate, whose description has been anticipated, as an example, in the previous chapter.

866 The importance of the seven evolutionary paths in the case study area, both in terms of surface

867 and number of plots (see the column "Total" in table 5.a and 5.b) is described as follow:

868 1. A share of plots accounting for $41.6 \%$ in number and for $46.4 \%$ in surface belong to

869 farms of the M class of adaptation capacity to external changes. This kind of intermediate

870 situation may evolve in any of the above mentioned farms evolutionary paths, namely

871 maintenance, multifunctionality, abandonment, or acquisition by other firms.

872 2. Almost a quarter (22.7\%) of plots, accounting for $19.1 \%$ of the total territory surface,

873 belong to the $\mathrm{MH}$ class and it is directed towards a multifunctional agriculture.

874 3. About a fifth (19.9\%) of plots i.e. $18.5 \%$ of the total study areas, is included in the VL

875 adaptation class whose land quite likely would either be abandoned or acquired by

876 stronger farms.

877 4. Some $11.7 \%$ of plots accounting for $11.2 \%$ in terms of surface belonged to the $\mathrm{H}$ class

878 and may evolve from the maintenance of current state to an increase of

879 multifunctionality.

8805 . Only $4 \%$ of plots accounting for $4.8 \%$ in terms of surface belongs to class L.

881 6. There are no plot either in the class $\mathrm{LM}$ or $\mathrm{VH}$

882 Tables 5.a and 5.b present the importance of the seven evolutionary paths in total and their 883 break-down according to the level of sensitivity of the landscape subsystem where they are 884 located. 
886 evolutionary paths and landscape sensitivity - absolute (unit and hectares) and relative (\%)

$887 \quad$ values

\begin{tabular}{|c|c|c|c|c|c|c|c|c|c|}
\hline \multirow{3}{*}{$\begin{array}{c}\text { Part a) } \\
\text { Number }\end{array}$} & & \multicolumn{8}{|c|}{ LANDSCAPE SENSITIVITY } \\
\hline & & \multicolumn{4}{|c|}{ Absolute values (number) } & \multicolumn{4}{|c|}{ Relative values $\%$} \\
\hline & & High & $\begin{array}{c}\text { Mediu } \\
\mathrm{m}\end{array}$ & Low & Total & High & $\begin{array}{l}\text { Mediu } \\
\mathrm{m}\end{array}$ & Low & Total \\
\hline \multirow{7}{*}{$\begin{array}{c}\text { Farms } \\
\text { evolutionar } \\
\text { y paths } \\
\text { (farms } \\
\text { adaptation } \\
\text { capacity) }\end{array}$} & VL & 450 & 342 & 0 & 792 & 11.3 & 8.6 & 0.0 & 19.9 \\
\hline & $\mathrm{L}$ & 152 & 8 & 0 & 160 & 3.8 & 0.2 & 0.0 & 4.0 \\
\hline & LM & 0 & 0 & 0 & 0 & 0.0 & 0.0 & 0.0 & 0.0 \\
\hline & M & 1115 & 534 & 2 & 1651 & 28.1 & 13.4 & 0.1 & 41.6 \\
\hline & $\mathrm{MH}$ & 267 & 630 & 6 & 903 & 6.7 & 15.9 & 0.2 & 22.7 \\
\hline & $\mathrm{H}$ & 344 & 121 & 0 & 465 & 8.7 & 3.0 & 0.0 & 11.7 \\
\hline & $\mathrm{VH}$ & 0 & 0 & 0 & 0 & 0.0 & 0.0 & 0.0 & 0.0 \\
\hline Number & Total & 2328 & 1635 & 8 & 3971 & 58.6 & 41.2 & 0.2 & 100.0 \\
\hline \multirow{2}{*}{$\begin{array}{l}\text { Part b) } \\
\text { Surface }\end{array}$} & & \multicolumn{4}{|c|}{ Absolute values (hectares) } & \multicolumn{4}{|c|}{ Relative values \% } \\
\hline & & High & $\begin{array}{c}\text { Mediu } \\
\mathrm{m}\end{array}$ & Low & Total & High & $\begin{array}{l}\text { Mediu } \\
\mathrm{m}\end{array}$ & Low & Total \\
\hline \multirow{7}{*}{$\begin{array}{l}\text { Farms } \\
\text { evolutionar } \\
\text { y paths } \\
\text { (farms } \\
\text { adaptation } \\
\text { capacity) }\end{array}$} & VL & 636.0 & 387.5 & 0.0 & 1023.5 & 11.5 & 7.0 & 0.0 & 18.5 \\
\hline & $\mathrm{L}$ & 251.0 & 14.20 & 0.0 & 265.20 & 4.5 & 0.3 & 0.0 & 4.8 \\
\hline & LM & 0.0 & 0.0 & 0.0 & 0.0 & 0.0 & 0.0 & 0.0 & 0.0 \\
\hline & $\mathrm{M}$ & $\begin{array}{r}1783 . \\
2\end{array}$ & 759.0 & 21.2 & 2563.4 & 32.3 & 13.7 & 0.4 & 46.4 \\
\hline & $\mathrm{MH}$ & 342.9 & 692.9 & 19.9 & 1055.7 & 6.2 & 12.5 & 0.4 & 19.1 \\
\hline & $\mathrm{H}$ & 505.4 & 111.7 & 0.0 & 617.10 & 9.1 & 2.0 & 0.0 & 11.2 \\
\hline & $\mathrm{VH}$ & 0.0 & 0.0 & 0.0 & 0.0 & 0.0 & 0.0 & 0.0 & 0.0 \\
\hline Surface & Total & $\begin{array}{r}3518 . \\
5\end{array}$ & 1965.3 & 41.1 & 5524.9 & 63.7 & 35.6 & 0.7 & 100.0 \\
\hline
\end{tabular}

888 Figure 6 shows the geographical distribution of the analysed farms, in relation to their more

889 likely evolutionary paths, based on their capacity of reaction to the external changes, and the 890 suitability to cultivation of their plots. 


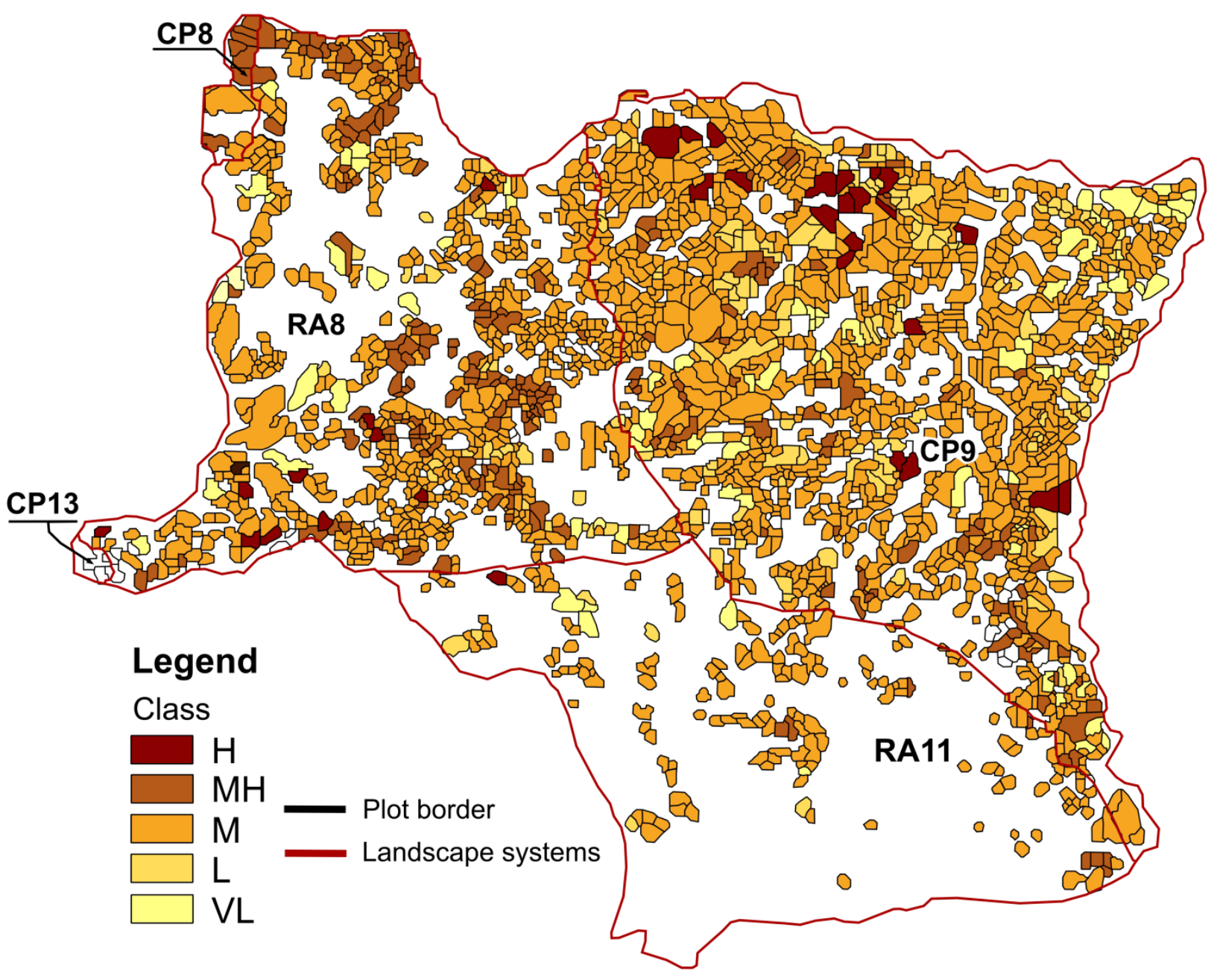

891

892 Figure 6. Spatial distribution of classes related to farms evolutionary paths7.

893 Farms able to adopt a strategy of multifunctionality reinforcement are 59 and account for a

894 surface of 1055 hectares, while farms with high risk of agricultural abandonment are 24 and

895 account for a surface of 1023 hectares. Class $\mathrm{H}$ includes 16 farms that show an intermediate

896 situation between the present status maintenance and multifunctionality reinforcement. Only 7

897 farms belong to the L-class and their evolution will likely vary from land abandonment to plots

898 acquisition by stronger firms. All the other farms belong to the class M and occupy a surface of

8992600 hectares.

$7 \mathrm{VH}$ and LM classes have been omitted, since they are not present in the case-study area 
900 Farms directed to multifunctionality are diffused on the western part of the study areas, whereas

901 the ones with a high risk of agricultural abandonment are concentrated in the central and in the

902 eastern part of Castiglione d'Orcia municipality. Finally, those farms whose prevalent evolution

903 will likely be the status quo maintenance are mainly located in the northern part of the study

904 area.

905 The results of farm analysis and their discussion with local stakeholders consent to derive some 906 important remarks about the territory under study:

907 1. The local entrepreneurial class appears quite stable as a considerable percentage of farms 908 presents a high adaptation capacity to the external transformations.

9092 2. The potential impacts on environmental and landscape resources are anyway very critical 910 as 4356 hectares, on a total surface of 5600 , belong to farms run by farmers that may opt 911 for agricultural abandonment if the external conditions (changes on CAP, market trends 912 and the effects of climate change) become too adverse.

913 From a qualitative point of view, the results of the participative approach confirm a different

914 attitude of organic farmers, in respect to conventional farmers, towards multifunctionality and

915 agricultural impacts on landscape. Indeed, while very often conventional farmers consider

916 landscape as a "by-product" of productive choices depending exclusively on market trends,

917 organic farmers have a more holistic approach and tend to consider the impact of their choices on

918 landscape, beyond bare economic convenience. This shows that the assumption made by some

919 policies that maintaining agricultural activity could insure also the maintenance of a good quality

920 landscape is not always true, but strongly depends on farmers attitude about the value of

921 landscape. 


\section{$922 \quad 3.3$ The individuation of specific and effective response actions}

923 Response actions depend both on territorial analysis and farm analysis results. As Table 6 shows,

924 e.g. in a subsystem with high landscape sensitivity, depending on farms probable evolution, the

925 response actions to counteract negative effects may vary from public institution actions for the

926 promotion of the territory, to specific regulations and incentives for the preservation of landscape

927 current state, up to incentives to improve farm viability in the specific territorial context. Public

928 promotion could, e.g. include such interventions as the creation or improvement of existing

929 countryside walking paths in order to improve territory and landscape fruition.

930 Table 6. Response actions for the sustainable governance of the case-study rural landscape

\begin{tabular}{|c|c|c|c|}
\hline \multirow{2}{*}{$\begin{array}{l}\text { Farm adaptation } \\
\text { capacity (resulting } \\
\text { from farm analysis) }\end{array}$} & \multicolumn{3}{|c|}{$\begin{array}{c}\text { Landscape sensitivity } \\
\text { (resulting from territorial analysis) }\end{array}$} \\
\hline & High & Medium & Low \\
\hline $\begin{array}{c}\mathbf{H} \\
\text { Maintenance }\end{array}$ & $\begin{array}{l}\text { Public promotion } \\
\text { actions }\end{array}$ & $\begin{array}{c}\text { Incentives aiming } \\
\text { to improve quality } \\
\text { of landscape }\end{array}$ & $\begin{array}{c}\text { Incentives aiming } \\
\text { to improve quality } \\
\text { of landscape }\end{array}$ \\
\hline $\begin{array}{c}\mathbf{M H} \\
\text { Multi-functionality }\end{array}$ & $\begin{array}{l}\text { Incentives aiming } \\
\text { to promote } \\
\text { multifunctionality }\end{array}$ & $\begin{array}{l}\text { Incentives aiming } \\
\text { to promote } \\
\text { multifunctionality } \\
\text { and to improve } \\
\text { quality of } \\
\text { landscape }\end{array}$ & $\begin{array}{l}\text { Incentives aiming } \\
\text { to improve quality } \\
\text { of landscape }\end{array}$ \\
\hline $\begin{array}{c}\mathbf{M} \\
\text { Uncertain strategies }\end{array}$ & $\begin{array}{l}\text { Incentives aiming } \\
\text { to maintain } \\
\text { agriculture } \\
\text { activities and / or } \\
\text { promote } \\
\text { multifunctionality }\end{array}$ & $\begin{array}{l}\text { Incentives aiming } \\
\text { to maintain } \\
\text { agriculture } \\
\text { activities and to } \\
\text { improve landscape } \\
\text { quality }\end{array}$ & $\begin{array}{l}\text { Incentives aiming } \\
\text { to maintain } \\
\text { agriculture } \\
\text { activities and to } \\
\text { improve landscape } \\
\text { quality }\end{array}$ \\
\hline $\begin{array}{c}\mathbf{L} \\
\text { Transfer to stronger } \\
\text { farms/abandonment }\end{array}$ & $\begin{array}{l}\text { Incentives aiming } \\
\text { to promote } \\
\text { entrepreneurial } \\
\text { "cultural change" }\end{array}$ & $\begin{array}{l}\text { Incentives aiming } \\
\text { to promote } \\
\text { entrepreneurial } \\
\text { "cultural change" } \\
\text { and to improve } \\
\text { landscape quality }\end{array}$ & $\begin{array}{l}\text { Low priority } \\
\text { interventions }\end{array}$ \\
\hline $\begin{array}{c}\mathbf{V L} \\
\text { Abandonment }\end{array}$ & $\begin{array}{l}\text { Incentives to } \\
\text { promote } \\
\text { entrepreneurial } \\
\text { "cultural change" }\end{array}$ & $\begin{array}{l}\text { Incentives aiming } \\
\text { to promote } \\
\text { entrepreneurial } \\
\text { "cultural change" } \\
\text { and to improve } \\
\text { landscape quality }\end{array}$ & $\begin{array}{l}\text { Low priority } \\
\text { interventions }\end{array}$ \\
\hline
\end{tabular}


931 Besides compulsory and voluntary tools, the actions to be implemented relates also to cultural

932 change both at entrepreneurial level and as regards the awareness of the importance of landscape

933 management. In this case ES provision is pursued not by aid or constraints but spreading a

934 positive attitude towards sustainability issues with the so-called "information instruments" or

935 "sermons" (van Zanten et al. 2013). Steering intrinsic motivation represents an action that has

936 more lasting effects and could reinforce the effects of other types of policies (mainly voluntary

937 ones), nevertheless it usually asks for a longer time in order to give effects and this should be

938 kept in mind in cases where faster responses are needed. The need of a GIS, able to collect and

939 update all farm changes, is a consequence of the above defined response actions, since it is

940 essential, especially for the monitoring of the most critical areas. Due to the adopted spatial

941 scale, all those actions can be calibrated not only at farm level, but also at plot level, which

942 makes such interventions potentially very effective.

943 Table 5.a and 5.b presented in the previous paragraph highlight that the majority of plots present

944 high landscape sensitivity and belong to the class $\mathrm{M}$ in relation to the farm analysis. In such

945 circumstances the definition of rules and incentives for the preservation of the current landscape

946 configuration, together with public promotion actions for landscape valorisation, becomes

947 absolutely necessary. A considerable number of plots present medium landscape sensitivity and

948 are included in the class $\mathrm{MH}$ in accordance with the farm analysis: in their cases the adoption of

949 regulations and incentives for the maintenance of landscape actual state are very appropriate.

950 About 630 hectares of the study area (correspondent to 450 plots) have a high landscape

951 sensitivity and belong to the class VL (Very Low) as for the farm analysis: this situation requires

952 the definition of specific actions able to help agriculture as well as the devising of instruments 
953 for the public promotion of landscape and typical or origin denomination agricultural products,

954 in order to support farms persistence in such difficult circumstances.

955 In addition to the definition of some dedicated interventions for the landscape subsystems, the

956 model enables to go into higher details, up to the identification of response action specific to

957 each farm, especially in presence of large farms. Consequently, when it is necessary or useful,

958 the model consents to diversify the management of plots belonging to the same farms, but

959 located in areas with different landscape sensitivity.

960 Although the definition of proper actions for promoting a sustainable rural landscape is very

961 important, it is not possible to remain in the "scientific domain" but these actions have to be seen

962 in the normative and administrative context where they have to be implemented. As we have

963 previously stated, in Italy there are several policy instruments aimed at preserving and improving

964 landscape such as the decree law n. 42/2004, or "Codex of cultural heritage and landscape", and

965 its subsequent amendments, the financial incentives coming through the CAP, the law relating

966 the rules for land transformation and territorial governance, e.g. in Tuscany the Regional Law $\mathrm{N}^{\circ}$

967 65/2014 and, mainly, the "Piano Paesaggistico" i.e. Landscape Plan of Tuscany (Regione

968 Toscana, 2015).

969 As regards participation, Tuscany has issued a Regional Law about "Rules on the promotion of

970 participation in the formulation of regional and local policies" (Tuscany Region Law $\mathrm{N}^{\circ}$

971 69/2007). Although the Tuscany legislative context is considered as favourable, the results are

972 sometimes considered as unsatisfactory. Gaggio (2014), in a paper focusing on Orcia Valley,

973 affirms that "Tuscany is indeed the site of layers, of normative constraints and guidelines,

974 ranging from local zoning regulations to the expectations associated with UNESCO's World

975 Heritage Site status" and that "Rural Tuscany has become both a paragon of harmonious beauty 
and a terrain of legal conflict and recrimination”. Besides, according to the evaluation promoted

977 by the Italian Ministry of Agriculture Food and Forestry Policies (MIPAAF, 2009) on the role of

978 landscape inside the Regional Development Programmes (RDPs) 2007-2013, Tuscany, albeit its

979 very good reputation about landscape and the policies aiming at preserving and improving it, has

980 a very poor evaluation regarding the specific measures relating landscape. This report affirms

981 that, although the Tuscany RDP is one of those where landscape is more cited, nevertheless its

982 specific measures seem, from the one hand to promote a further reforestation and renaturalisation

983 (although current share of forested land is higher than it was in the past, see Agnoletti, 2014),

984 and, from the other hand, to consider landscape as an output that is "automatically" guaranteed

985 by any type of agriculture, also in the case that farmers aim only at a rationalisation from a

986 technical and productive point of view. Nevertheless, we have already stressed that not all

987 farmers have a multifunctional attitude towards landscape management. However, landscape is

988 something that is very difficult to manage with traditional tools; indeed, as stated by many

989 Authors (e.g. Agnoletti et al., 2011) "it cannot be presumed in the Regional Rural Development

990 Plans that hedges and rows of trees are always positive for the landscape; this can only be

991 established if a study, at local level, identifies them as important elements of the landscape

992 identity". This is also the case of Val d'Orcia where foreign land owners have spread traditional

993 elements of the Tuscany landscape (e.g. Cupressus rows) in ways and amounts that are in

994 contrast with the traditional landscape of the area. Last but not least, proper landscape and

995 agricultural policies would very often benefit from a zoning that is more detailed than the usual

996 one and that could make it possible to tailor interventions on the specific needs of an area. From

997 this point of view, the new rules for greening that are intended to be the same through all Europe

998 despite the differences in climate, agriculture and landscape of the EU countries, represent an 
999 approach that is everything but local, and put constraints on eventual regional and local

1000 managements of agriculture that could be more suitable for a specific area.

10014 Concluding remarks

1002 The implementation of ELC brought about the need for an interdisciplinary and transdisciplinary

1003 approach to the problems of landscape. From this point of view, the general governance model

1004 that we propose:

1005 - Represents an approach able to integrate methods and techniques belonging to different

1006 but complementary fields - as tools proper of social sciences (participative methods),

1007 territorial planning and environmental evaluation - and to cope with different time and

1008 spatial scales.

1009 - Highlight the importance of a real and direct involvement of social actors to bring about

1010 structural and long-term changes, thus making more effective the public expenditure.

1011 - Allows to single out and locate sub-regions where critical evolutions as regards the

1012 management of agricultural land, and consequently landscape modifications, may take

1013 place.

1014 Such results provide a fundamental, scientifically robust and flexible tool able to support public

1015 decision-makers for territorial planning interventions in an area. Indeed the model, when

1016 implemented, has to be adapted according to the specific features of an area, data availability,

1017 etc. This flexibility is a favourable characteristics insofar as "the efficacy of the rules that

1018 safeguard the maintenance of the characteristic elements of the landscape is strictly linked to the

1019 diversity and typicality of the landscape where they are applied and (...) the evaluation may only

1020 be conducted at local level" (Agnoletti et al., 2011). 
1021 The case-study of Castiglione d'Orcia Municipality represents a first simplified approach, since

1022 an extension to areas with different characteristics - especially in a process of integration of

1023 territorial planning and tools promoting the economic development - would ask for a more

1024 comprehensive analysis of environmental variables and for the definition of territorial ambits

1025 inside and not outside the model. Nevertheless, we think that it allows the readers to appreciate

1026 the potential usefulness of this tool in designing effective landscape policies at local level and in

1027 matching the policy-makers need for new tools, methods and guidance material (Conrad et al.,

1028 2011a). In recent literature there are many studies on landscape, but what is still missing is an

1029 effort to coordinate and organize all this knowledge in a way that could make it useful in terms

1030 of policy application.

1031 Although the "scientific analysis" is a first and important step, nevertheless it is not sufficient, by

1032 itself, to guarantee the transfer into appropriate operative actions aiming to improve landscape

1033 ecosystem services. Besides, while new guidelines in landscape policies ask for a new approach

1034 from researchers able to fill the gap in the field of more modern and holistic approaches to the

1035 landscape, it seems that operative policies have difficulties in abandoning the old approach

1036 linked to the preservation of areas just for their aesthetical and natural characteristics without

1037 taking into account the need to integrate landscape and landscape policies in a broader context

1038 and to coordinate them. In this framework, we think that in order to promote the governance of a

1039 sustainable rural landscape it would be necessary:

1040 - To create a proper data-base about environmental and socio-economic information at

1041 least at Regional level, able to provide detailed information at different geographic scales

1042 and times. In this framework every effort should be made to make the data/information

1043 easily and freely available for both administrative and research purposes. 
1044 - To promote participation, using also the tools of information technology, and properly

1045 integrate it in decision making processes.

1046 - To make planning and programming processes continuous and more flexible. Too often

1047 the "ad hoc" concertation requires too much time, so that when a plan or a programme is

1048 implemented it is already "too old"; this problem is worsened by the fact that these tools

1049 have often a very long life time-span.

1050 - To overcome the lack of coordination between different policy tools. Indeed, what is still

1051 missing in the Italian context is an operative policy approach able to integrate and

1052 coordinate instances coming from stakeholders, agricultural (or other sectoral) policies

1053 and territorial and landscape governance. Consequently efforts should be directed

1054 towards innovative policies and governance instruments, such as collective voluntary

1055 actions, integrated project, etc., which are needed for any adequate implementation of

1056 sustainable landscape and rural development policies.

1057 As regards this last issue, although the measures on landscape are still less important than in the

1058 previous RDP, Tuscany Region has included in the RDP 2014-2020 a measure relating

1059 Integrated Territorial Projects, whose implementation was permitted by the National

1060 Development Plan already in the previous RDPs. The Integrated Projects make it possible to

1061 coordinate the actions of many private and public subjects operating on the same territory

1062 according to a shared strategy and consequently could constitute a first attempt to pursue the

1063 above mentioned coordination.

\section{References}

Agnoletti, M. (2014). Rural landscape, nature conservation and culture: Some notes on research trends and management approaches from a (southern) European perspective. Landscape and Urban Planning, 126, 66-73. doi:10.1016/j.landurbplan.2014.02.012 
Agnoletti, M., Cargnello, G., Gardin, L., Santoro, A., Bazzoffi, P., Sansone, L., ... Belfiore, N. (2011). Traditional landscape and rural development: Comparative study in three terraced areas in northern, central and southern Italy to evaluate the efficacy of GAEC standard 4.4 of cross compliance. Italian Journal of Agronomy, 6(SUPL.1), 121-139. doi:10.4081/ija.2011.6.s1.e16

Agnoletti, M., \& Maggiari, G. (2004). La valutazione dell'impatto sul paesaggio e sul patrimonio storico, architettonico e archeologico. In Galeotti, Lorenzo, Grassi, Simona, Ugolini, Alberto, \& Zita, Fabio (Eds.), Regione Toscana, Linee guida per la valutazione dell'impatto ambientale degli impianti eolici (pp. 59-108). Firenze: Regione Toscana. Retrieved from http://www.landscape.unifi.it/pdf/linee_guida_via_impianti_eolici-1.pdf

Antrop, M. (2005). Why landscapes of the past are important for the future. In Landscape and Urban Planning, 70 (1/2), 21-34. doi:10.1016/j.landurbplan.2003.10.002

Beilin, R., Lindborg, R., Stenseke, M., Pereira, H. M., Llausàs, A., Slätmo, E., ... Queiroz, C. (2014). Analysing how drivers of agricultural land abandonment affect biodiversity and cultural landscapes using case studies from Scandinavia, Iberia and Oceania. Land Use Policy, 36, 60-72. doi:10.1016/j.landusepol.2013.07.003

Beinat, E., \& Nijkamp, P. (1998). Multicriteria analysis for land-use management. (E. Beinat \& P. Nijkamp, Eds.) Environment \& management. Springer Science \& Business Media.

Bellini N., Loffredo A., \& Pasquinelli C. (2011). Managing otherness: the political economy of place images in the case of Tuscany in Kavaratzis, M. \& Ashworth G. (Eds.) Brand Management for cities: The theory and practice of effective place branding, London, Edward Elgar, pp. 89-115

Boroushaki, S., \& Malczewski, J. (2010). Using the fuzzy majority approach for GIS-based multicriteria group decision-making. Computers and Geosciences, 36(3), 302-312. http://dx.doi.org/10.1016/j.cageo.2009.05.011

Brady, M., Kellermann, K., Sahrbacher, C., \& Jelinek, L. (2009). Impacts of decoupled agricultural support on farm structure, biodiversity and landscape mosaic: Some EU results. Journal of Agricultural Economics, 60(3), 563-585. doi:10.1111/j.1477-9552.2009.00216.x

Brunori, G., Cerruti, R., Rovai, M., Belletti, G., Marescotti, A., \& Neri, T. (2008).

Cambiamento delle politiche e strategie aziendali: i risultati di un'indagine degli effetti della riforma di medio termine sulla produzione del frumento duro in Toscana [Change of Policies and business strategies: results of a survey of the effects of the CAP mid-term review on the production of durum wheat in Tuscany]. In Agricolture e mercati in transizione [Agricultures and markets in transition]: atti del XLIII convegno di studi, Assisi, 7-9 settembre 2006 (pp. 313-332). Assisi: FrancoAngeli.

Conrad, E., Christie, M., \& Fazey, I. (2011a). Is research keeping up with changes in landscape policy? A review of the literature. Journal of Environmental Management, 92(9), 20972108. doi:10.1016/j.jenvman.2011.04.003

Conrad, E., Christie, M., \& Fazey, I. (2011b). Understanding public perceptions of landscape: A case study from Gozo, Malta. Applied Geography, 31(1), 159-170. http://dx.doi.org/10.1016/j.apgeog.2010.03.009

Corbelle-Rico, E., \& Crecente-Maseda, R. (2014). Evaluating IRENA indicator "Risk of Farmland Abandonment" on a low spatial scale level: The case of Galicia (Spain). Land Use Policy, 38, 9-15. doi:10.1016/j.landusepol.2013.10.013 
Costanza, R., d'Arge, R., de Groot, R., Farber, S., Grasso, M., Hannon, B., ... van den Belt, M. (1997). The value of the world's ecosystem services and natural capital. Nature, 387, 253260. Retrieved from http://www.esd.ornl.gov/benefits_conference/nature_paper.pdf.

Council of Europe. (2000). European Landscape Convention. Report and Convention Florence, ETS No. 17, 8. doi:http://conventions.coe.int/Treaty/en/Treaties/Html/176.htm

Council of European Communities. (1976). Council Regulation (EEC) No 3103/76 of 16

December 1976 on aid for durum wheat. OJ, L(351), 1-2.

De Groot, R. S., Alkemade, R., Braat, L., Hein, L., \& Willemen, L. (2010). Challenges in integrating the concept of ecosystem services and values in landscape planning, management and decision making. Ecological Complexity, 7(3), 260-272. doi:10.1016/j.ecocom.2009.10.006

Farina A. (2006). Principles and Methods in Landscape Ecology - Towards a Science of the Landscape. Springer.

Gaggio D. (2011). Selling Beauty: Tuscany's Rural Landscape since 1945 in N. Bandelj and F. Wherry (eds.), The Cultural Wealth of Nations, Palo Alto: Stanford University Press, 2011: 90-113

Gaggio D. (2014). Valuing place/placing value: the elusive normativity of landscape in rural Tuscany. Journal of Modern Italian Studies, 19(5), 556-569. doi:10.1080/1354571X.2014.962255

Gobattoni, F., Pelorosso, R., Leone A., \& Ripa M.N. (2015). Sustainable rural development: The role of traditional activities in Central Italy. Land Use Policy, 48, 412-427. doi:10.1016/j.landusepol.2015.06.013

Higgins, S., Mahon, M., \& McDonagh, J. (2012). Interdisciplinary interpretations and applications of the concept of scale in landscape research. Journal of Environmental Management, 113, 137-145. http://dx.doi.org/10.1016/j.jenvman.2012.08.027

Howley, P. (2011). Landscape aesthetics: Assessing the general publics' preferences towards rural landscapes. Ecological Economics, 72, 161-169. doi:10.1016/j.ecolecon.2011.09.026

Howley, P., Donoghue, C. O., \& Hynes, S. (2012). Exploring public preferences for traditional farming landscapes. Landscape and Urban Planning, 104(1), 66-74. doi:10.1016/j.landurbplan.2011.09.006

Ihse M. (1990). Air photo interpretation and computer cartography - tools for studying the cultural landscape. In D. Birks (Ed.), The Cultural Landscape: Past, Present and Future (pp. 153-164). Cambridge: Cambridge University Press.

Karsak, E. E. (2004). Fuzzy multiple objective decision making approach to prioritize design requirements in quality function deployment. International Journal of Production Research, 47, 149-163. doi:10.1016/j.cie.2004.06.001

Lefebvre M., Espinosa M., \& Gomez Paloma S.. (2012). The influence of the Common Agricultural Policy on agricultural landscapes. Luxembourg. doi:10.2791/94269

Lorenzini E. (2011). The Extra-urban Cultural District: An Emerging Local Production System: Three Italian Case Studies. European Planning Studies, 19:8, 1441-1457, doi:10.1080/09654313.2011.586179

Maccherini, S., Chiarucci, A., \& De Dominicis V. (1998). Relationships between vegetation and morphology in the Radicofani calanchi (southern Tuscany). Atti Museo Storia Naturale Maremma, 17, 91-108.

Malczewski, J. (1999). GIS and multicriteria decision analysis. (J. Malczewski, Ed.) Engineering (Vol. 31). Wiley. 
Malczewski, J. (2006a). GIS-based multicriteria decision analysis: a survey of the literature. International Journal of Geographical Information Science, 20(7), 703-726. doi:10.1080/13658810600661508

Malczewski, J. (2006b). Ordered weighted averaging with fuzzy quantifiers: GIS-based multicriteria evaluation for land-use suitability analysis. International Journal of Applied Earth Observation and Geoinformation, 8(4), 270-277. doi:10.1016/j.jag.2006.01.003

Marignani, M., Rocchini, D., Torri, D., Chiarucci, A., \& Maccherini, S. (2008). Planning restoration in a cultural landscape in Italy using an object-based approach and historical analysis. Landscape and Urban Planning, 84(1), 28-37. http://dx.doi.org/10.1016/j.landurbplan.2007.06.005

Mayes, R. (2010). Doing cultural work: Local postcard production and place identity in a rural shire. Journal of Rural Studies, 26(1), 1-11. doi:10.1016/j.jrurstud.2009.06.002

McNeely J. A., \& Keeton W. S. (1995). The Interaction between Biological and Cultural Diversity. In R. M. von Droste B. (Ed.), Cultural Landscape of Universal Value (pp. 2537). New York: Gustav Fischer Verlag.

Mendoza, G. A., \& Martins, H. (2006). Multi-criteria decision analysis in natural resource management: A critical review of methods and new modelling paradigms. Forest Ecology and Management, 230(1-3), 1-22, doi:10.1016/j.foreco.2006.03.023.

Miele, M., \& Murdoch, J. (2002). The Practical Aesthetics of Traditional Cuisines: Slow Food in Tuscany. Sociologia Ruralis, 42(4), 312-328. doi:10.1111/1467-9523.00219

MIPAAF, Paesaggio e Sviluppo Rurale. Il ruolo del paesaggio all'interno dei Programmi di Sviluppo Rurale 2007-2013, 2009, (Italian Ministry of Agriculture, Food and Forestry. Landscape and Rural Development. The role of landscape in Rural Development Programmes 2007-2013) Retrieved from http://landscapeunifi.it/images/pdf/PSR_2007_2013_paesaggio.pdf

Mopurgo, Andrea (2005), Brandlandscape system. Strategies of landscape design under the effects of globalize markets. Retrieved January 26, 2016 from http://designhistoryforum.org/dd/papers/vol01/no1/01_1_54_62.pdf

Neri, T., Brunori, G., Rovai, M., Belletti, G., Marescotti, A., \& Pacciani, A. (2008). Durum Wheat in Tuscany. In F. Arfini, G. Belletti, F. Giarè, \& A. Marescotti (Eds.), Socioeconomic impact of decoupling and food-chain perspective: some indications from Italy (pp. 39-71). Naples: Edizioni Scientifiche Italiane.

OECD, Paris. «Multifunctionality : towards an analytical framework | Clc», 2001. http://www.oecd.org/agriculture/agricultural-policies/1894469.pdf.

Phillips, C. P. (1998). The Crete Senesi, Tuscany a vanishing landscape? Landscape and Urban Planning, 41(1), 19-26. doi:10.1016/S0169-2046(98)00052-8

Piorr, A., Ungaro, F., Ciancaglini, A., Happe, K., Sahrbacher, A., Sattler, C., ... Zander, P. (2009). Integrated assessment of future CAP policies: land use changes, spatial patterns and targeting. Environmental Science \& Policy, 12(8), 1122-1136. doi:10.1016/j.envsci.2009.01.001

Regione Toscana. (n.d.). 4. Allegati documentali per la disciplina paesaggistica - Paesaggio Pianificazione e paesaggio - Enti e associazioni - Regione Toscana. ATLANTE DEI PAESAGGI TOSCANI. Institutional. Retrieved April 17, 2014, from http://www.regione.toscana.it/-/4-allegati-documentali-per-la-disciplinapaesaggistica\#atlante 
Regione Toscana (2005). Legge n. 1/2005- Norme per il Governo del territorio, Bollettino Ufficiale Regione Toscana n. 2, parte prima, del 12 gennaio 2005 (Tuscany Region, Law n. $1 / 2005$ - Rules for the Government of the Territory)

Regione Toscana (2014). Legge n. 65/2014 - Norme per il Governo del Territorio, Bollettino Ufficiale della Regione n. 53, parte prima, del 12 novembre 2014 (Tuscany Region, Law n. 65/2014 - Rules for the Government of the Territory)

Regione Toscana (2015). Piano di indirizzo territoriale con valenza di piano paesaggistico. Deliberazione Consiglio Regionale 27 marzo 2015, n.37 (Tuscany Region, Plan of Territorial Guidance with value as Landscape plan. Regional Council Deliberation N. 27, March 2015)

Robertson, G. P. \& Swinton S. M. (2005). Reconciling Agricultural Productivity and Environmental Integrity: A Grand Challenge for Agriculture. Frontiers in Ecology and the Environment 3(1), 38-46. doi:10.1890/1540-9295(2005)003[0038:RAPAEI]2.0.CO;2.

Rossi R, Merendi G. A., \& Vinci A. (1994). I Sistemi di Paesaggio della Toscana. Firenze: Tipografia della Giunta Regionale Toscana. Retrieved from http://www.ecoitaly.net/sva/2003/sistemi_paesaggio.htm

Rossi, R., \& Vos, W. (1993). Criteria for the identification of a Red List of Mediterranean landscapes: three examples in Tuscany. Landscape and Urban Planning, 24(1-4), 233-239. doi:10.1016/0169-2046(93)90102-J

Rössler M. (2010). World Heritage and Sustainable Development: the Case of Cultural Landscapes. . In \& M.-T. A. (Eds. . D. Offenhäußer (Ed.), World Heritage and Cultural Diversity (pp. 196-202). Cottbus: GmbH \& Co. KG. Retrieved from http://www.tucottbus.de/fakultaet3/fileadmin/uploads/interkulturalitaet/pdf/world_heritage_and_cultural diversity.pdf

Rovai, M. (1994). Il comparto cerealicolo delle Colline Pisano-Livornesi: un'analisi attraverso i fenomeni di strutturazione e ristrutturazione delle aziende cerealicole e dei canali di commercializzazione locali. In A. Panattoni (Ed.), La sfida della moderna ruralità: agricoltura e sviluppo integrato del territorio: il caso delle colline pisane e livornesi (pp. 299-366). Pisa: CNR-RAISA.

Saaty, T. L. (1980). The Analytic Hierarchy Process. Education, New York: McGraw Hill pp. 111.

Saaty, T. L. (2004). Decision making — the Analytic Hierarchy and Network Processes (AHP/ANP). Journal of Systems Science and Systems Engineering, 13(1), 1-35, retrieved from http://link.springer.com/article/10.1007\%2Fs11518-006-0151-5\#/page-1

Saaty, T. L. (2008). Decision making with the analytic hierarchy process. International Journal of Services Sciences, 1(1), 83. doi:10.1504/IJSSCI.2008.017590

Saaty T. L., \& Vargas L. G. (1994). Decision making in economic, political, social, and technological environments with the analytic hierarchy process. Pittsburgh: RWS Publications.

Sangalli, A. (1998). The importance of being fuzzy: and other insights from the border between math and computers. Princeton: Princeton University Press.

Scott, A. (2011). Beyond the conventional: Meeting the challenges of landscape governance within the European Landscape Convention? Journal of Environmental Management, 92(10), 2754-2762. doi:10.1016/j.jenvman.2011.06.017

Sereni, E. (1997). History of the Italian agricultural landscape. (R. B. Litchfield, Trans.). Princeton, N.J.: Princeton University Press. 
Sevenant, M., \& Antrop, M. (2010). Transdisciplinary landscape planning: Does the public have aspirations? Experiences from a case study in Ghent (Flanders, Belgium). Land Use Policy, 27(2), 373-386. doi:10.1016/j.landusepol.2009.05.005

Shannon C. E., \& Weaver W. (1949). The mathematical theory of communication. Urbana: University of Illinois Press.

Sharpe D. M., Stearns F., Burgess R. L., \& Johnson W. C. (1982). Spatio-temporal patterns of forest ecosystems in mandominated landscapes of eastern United States. In S. P. Tjallingii \& A. A. de Veer (Eds.), Perspectives in landscape ecology (pp. 109-116). Wageningen [The Netherlands]: : Pudoc: Centre for Agricultural Pub. and Documentation.

Siddiqui M. Z., Everett J. W., \& Vieux, B. E. (1996). Landfill Siting Using Geographic Information Systems: A Demonstration. Journal of Environmental Engineering, 122(6), 513-523. doi:10.1061/(ASCE)0733-9372(1996)122:6(515)

Soneryd, L. (2004). Public involvement in the planning process: EIA and lessons from the Orebro airport extension, Sweden. Environmental Science and Policy, 7(1), 59-68. doi:10.1016/j.envsci.2003.10.007

Southern, A., Lovett, A., O’Riordan, T., \& Watkinson, A. (2011). Sustainable landscape governance: Lessons from a catchment based study in whole landscape design. Landscape and Urban Planning, 101(2), 179-189. http://dx.doi.org/10.1016/j.landurbplan.2011.02.010

Tempesta, T. (2010). The perception of agrarian historical landscapes: A study of the Veneto plain in Italy. Landscape and Urban Planning, 97(4), 258-272. doi:10.1016/j.landurbplan.2010.06.010

Tempesta T.. (2014). People's preferences and landscape evaluation in Italy: a review. New Medit, 1, Edizioni Dedalo S R L, pp 50-59. Retrieved from http://www.scopus.com/inward/record.url?eid=2-s2.0-84899503365\&partnerID=tZOtx3y1

UNESCO. «The World Heritage Convention». Institutional. UNESCO World Heritage Convention, 1972. http://whc.unesco.org/en/convention/

Van Assche, K., \& Lo, M. C. (2011). Planning, preservation and place branding: A tale of sharing assets and narratives. Place Branding and Public Diplomacy, 7(2), 116-126.

Van Mansvelt, J.D. \& Van der Lubbe, M.D. (1999). Checklist for Sustainable Landscape Management. Final report of the EU concerted action AIR5-CT93-1210: The Landscape and Nature Production Capacity of Organic/Sustainable Types of Agriculture, Elsevier, Amsterdam, 1999

Van Zanten, B. T., Verburg, P. H., Espinosa, M., Gomez-y-Paloma, S., Galimberti, G., Kantelhardt, J., ... Viaggi, D. (2013). European agricultural landscapes, common agricultural policy and ecosystem services: a review. Agronomy for Sustainable Development, 34(2), 309-325. doi:10.1007/s13593-013-0183-4

Vargas, L. G. (1990). An overview of the analytic hierarchy process and its applications. European Journal of Operational Research, 48(1), 2-8. doi:10.1016/0377-2217(90)90056$\mathrm{H}$

Vizzari, M. (2011). Spatial modelling of potential landscape quality. Applied Geography, 31(1), 108-118. http://dx.doi.org/10.1016/j.apgeog.2010.03.001

WCED (1987). Our common future. Oxford University Press, New York (Bruntland Report)

Wu J. (2013). Landscape sustainability science: ecosystem services and human well-being in changing landscapes, Landscape Ecology, 28, 999-1023. doi:10.1007/s10980-013-9894-9 


\section{WEB References}

http://dati-censimentoagricoltura.istat.it/ - Italian Institute of Statistics, Data warehouse of the $6^{\text {th }}$ Agricultural Census 2010, last consulted 24 February 2016

http://dati-censimentopopolazione.istat.it/ - Italian Institute of Statistics, Data warehouse of the

$15^{\text {th }}$ Population Census 2011, last consulted 24 February 2016

http://www.igmi.org/prodotti/ortofotocarte.php - Italian Military Geographic Institute -

Orthophotocartographies, last consulted 24 February 2016

http://www.istat.it/it/archivio/150249 - Italian Institute of Statistics, Early estimates for crops

(Indagine sulle intenzioni di semina degli agricoltori), agricultural campaign 2014-2015"

(data for other campaigns are available), last consulted 24 February 2016

http://www.provincia.siena.it/index.php/Aree-tematiche/Turismo/Osservatorio-

turistico/Movimentazione-statistica - Siena province statistics from the Siena Observatory

on Tourism, last consulted 24 February 2016

http://www.regione.toscana.it/documents/10180/70960/ATLANTE\%20DEI\%20PAESAGGI\%2

OTOSCANI\%20val\%20d'orcia/69995032-581b-46fe-b856-8a4b4b20ecf9 - Tuscany

Region, Atlas of Rural landscapes: Val d'Orcia, last consulted 24 February 2016

http://www502.regione.toscana.it/geoscopio/servizi/wms/OFC.htm - Tuscany Region GIS,

consultation services of orthophotos, last consulted 24 February 2016 